NASA/TM-2000-209015

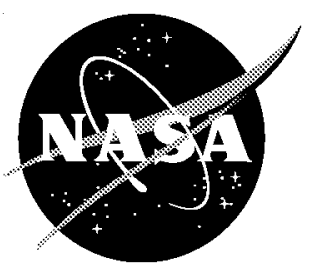

\title{
A Real-Time Method for Estimating Viscous Forebody Drag Coefficients
}

Stephen A. Whitmore and Marco Hurtado

NASA Dryden Flight Research Center

Edwards, California

Jose Rivera

University of South Florida

Tampa, Florida

Jonathan W. Naughton

University of Wyoming

Laramie, Wyoming 


\section{The NASA STI Program Office...in Profile}

Since its founding, NASA has been dedicated to the advancement of aeronautics and space science. The NASA Scientific and Technical Information (STI) Program Office plays a key part in helping NASA maintain this important role.

The NASA STI Program Office is operated by Langley Research Center, the lead center for NASA's scientific and technical information. The NASA STI Program Office provides access to the NASA STI Database, the largest collection of aeronautical and space science STI in the world. The Program Office is also NASA's institutional mechanism for disseminating the results of its research and development activities. These results are published by NASA in the NASA STI Report Series, which includes the following report types:

- TECHNICAL PUBLICATION. Reports of completed research or a major significant phase of research that present the results of NASA programs and include extensive data or theoretical analysis. Includes compilations of significant scientific and technical data and information deemed to be of continuing reference value. NASA's counterpart of peer-reviewed formal professional papers but has less stringent limitations on manuscript length and extent of graphic presentations.

- TECHNICAL MEMORANDUM. Scientific and technical findings that are preliminary or of specialized interest, e.g., quick release reports, working papers, and bibliographies that contain minimal annotation. Does not contain extensive analysis.

- CONTRACTOR REPORT. Scientific and technical findings by NASA-sponsored contractors and grantees.
- CONFERENCE PUBLICATION.

Collected papers from scientific and technical conferences, symposia, seminars, or other meetings sponsored or cosponsored by NASA.

- SPECIAL PUBLICATION. Scientific, technical, or historical information from NASA programs, projects, and mission, often concerned with subjects having substantial public interest.

- TECHNICAL TRANSLATION. Englishlanguage translations of foreign scientific and technical material pertinent to NASA's mission.

Specialized services that complement the STI Program Office's diverse offerings include creating custom thesauri, building customized databases, organizing and publishing research results...even providing videos.

For more information about the NASA STI Program Office, see the following:

- Access the NASA STI Program Home Page at http://www.sti.nasa.gov

- E-mail your question via the Internet to help@sti.nasa.gov

- Fax your question to the NASA Access Help Desk at (301) 621-0134

- Telephone the NASA Access Help Desk at (301) 621-0390

- Write to:

NASA Access Help Desk

NASA Center for AeroSpace Information 7121 Standard Drive

Hanover, MD 21076-1320 


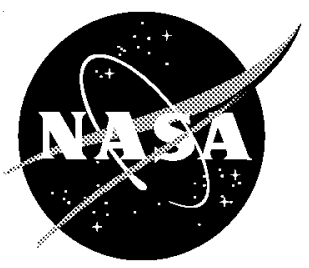

\section{A Real-Time Method for Estimating Viscous Forebody Drag Coefficients}

Stephen A. Whitmore and Marco Hurtado

NASA Dryden Flight Research Center

Edwards, California

Jose Rivera

University of South Florida

Tampa, Florida

Jonathan W. Naughton

University of Wyoming

Laramie, Wyoming

National Aeronautics and

Space Administration

Dryden Flight Research Center

Edwards, California 93523-0273 


\section{NOTICE}

Use of trade names or names of manufacturers in this document does not constitute an official endorsement of such products or manufacturers, either expressed or implied, by the National Aeronautics and Space Administration.

Available from the following:

NASA Center for AeroSpace Information (CASI)

7121 Standard Drive

Hanover, MD 21076-1320

(301) 621-0390
National Technical Information Service (NTIS) 5285 Port Royal Road Springfield, VA 22161-2171 (703) $487-4650$ 


\title{
A REAL-TIME METHOD FOR ESTIMATING VISCOUS FOREBODY DRAG COEFFICIENTS
}

\author{
Stephen A. Whitmore* and Marco Hurtado ${ }^{\dagger}$ \\ NASA Dryden Flight Research Center \\ Edwards, California \\ Jose Rivera \\ University of South Florida \\ Tampa, Florida \\ Jonathan W. Naughton ${ }^{\S}$ \\ University of Wyoming \\ Laramie, Wyoming
}

\begin{abstract}
$\underline{\text { Abstract }}$
This paper develops a real-time method based on the law of the wake for estimating forebody skin-friction coefficients. The incompressible law-of-the-wake equations are numerically integrated across the boundary layer depth to develop an engineering model that relates longitudinally averaged skin-friction coefficients to local boundary layer thickness. Solutions applicable to smooth surfaces with pressure gradients and rough surfaces with negligible pressure gradients are presented. Model accuracy is evaluated by comparing model predictions with previously measured flight data. This integral law procedure is beneficial in that skinfriction coefficients can be indirectly evaluated in realtime using a single boundary layer height measurement. In this concept a reference pitot probe is inserted into the flow, well above the anticipated maximum thickness of the local boundary layer. Another probe is servomechanism-driven and floats within the boundary layer. A controller regulates the position of the floating probe. The measured servomechanism position of this second probe provides an indirect measurement of both local and longitudinally averaged skin friction.
\end{abstract}

\footnotetext{
*Aerospace Engineer, Associate Fellow, ALAA.

${ }^{\dagger}$ Co-operative Education Engineering Student Intern, Aejodynamics Branch.

Engineering Student Intern, Department of Mechanical Engineering.

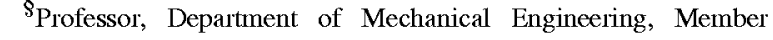
AIAA.

Copyright (C) 2000 by the American Institute of Aeronautics and Astronautics, Inc. No copyright is asserted in the United States under Title 17, U.S. Code. The U.S. Government has a royalty-free license to exercise all rights under the copyright claimed herein for Governmental purposes. All other rights are reserved by the copyright owner.
}

Simulation results showing the performance of the control law for a noisy boundary layer are then presented.

\section{$\underline{\text { Nomenclature }}$}

$A_{k} \quad$ control equation coefficient

$B \quad$ law of the wake bias parameter

$B_{k} \quad$ control equation coefficient

$C_{D_{\text {base }}} \quad$ base drag coefficient

$C_{D_{\text {total }}} \quad$ total drag coefficient

$C_{F} \quad$ longitudinally averaged skin friction coefficient, $C_{F}=\frac{1}{x} \int_{0}^{x} c_{f} d x$

$C_{k} \quad$ control equation coefficient

$c_{f} \quad$ local skin friction coefficient

$c_{f_{\text {nonlinear }}}$ local skin friction coefficient calculated by the nonlinear solution method

$c_{f_{\text {closed form }}}$ local skin friction coefficient calculated by the closed-form solution method

$\hat{C}_{F} \quad$ estimated skin friction coefficient

$C_{0} \quad$ curve fit bias coefficient

$C_{1}$

$d x$

$d y$

$G\left[\frac{x}{\kappa_{s}}\right]$

curve fit slope coefficient

longitudinal integration variable

normal integration variable

rough surface, skin friction ratio parameter, $G\left[\frac{x}{\kappa_{s}}\right]=\frac{C_{f}}{C_{F}}$

$F \quad$ law-of-the-wake velocity defect function, $\mathrm{m} / \mathrm{sec}$ 


\begin{tabular}{|c|c|c|c|}
\hline$K$ & gain parameter & $w$ & longitudinal lateral in boundary layer, \\
\hline$k$ & discrete time index & & \\
\hline $\mathrm{kPa}$ & kilopascals & $w^{\prime}$ & $\begin{array}{l}\text { unsteady perturbation of lateral velocity, } \\
\mathrm{m} / \mathrm{sec}\end{array}$ \\
\hline$M_{e d g e}$ & Mach number at edge of boundary layer & $x$ & longitudinal coordinate, $\mathrm{cm}$ \\
\hline$m$ & boundary layer velocity profile exponent & $y$ & normal boundary layer coordinate, $\mathrm{cm}$ \\
\hline$n$ & control gain parameter & $y_{\text {final }}$ & steady-state probe position, $\mathrm{cm}$ \\
\hline $\bar{q}$ & $\begin{array}{l}\text { local dynamic pressure within boundary } \\
\text { layer, } \mathrm{kPa}\end{array}$ & $y_{k}$ & current probe position, $\mathrm{cm}$ \\
\hline $\bar{q}_{e}$ & \multirow{2}{*}{$\begin{array}{l}\text { dynamic pressure at edge of boundary } \\
\text { layer, } \mathrm{kPa}\end{array}$} & $y_{k+1}$ & commanded probe position, $\mathrm{cm}$ \\
\hline & & $y_{k-1}$ & old probe position, $\mathrm{cm}$ \\
\hline$\left[\frac{\bar{q}}{\bar{q}_{e}}\right]$ & $\begin{array}{l}\text { steady-state dynamic pressure ratio } \\
\text { promeasured dynamic pressure, } \mathrm{kPa}\end{array}$ & $y_{l a m}$ & $\begin{array}{l}\text { normal displacement within laminar } \\
\text { sublayer, } \mathrm{cm}\end{array}$ \\
\hline $\bar{q}_{\text {meas }}$ & reference dynamic pressure, $\mathrm{kPa}$ & $y_{\text {probe }}$ & probe position in boundary layer, $\mathrm{cm}$ \\
\hline $\begin{array}{l}\bar{q}_{\text {ref }} \\
\bar{q}_{\text {steady }}\end{array}$ & $\begin{array}{l}\text { steady dynamic pressure in steady } \\
\text { boundary layer }\end{array}$ & $y_{\text {trans }}$ & $\begin{array}{l}\text { point of transition between laminar and } \\
\text { turbulent layers }\end{array}$ \\
\hline $\bar{q}_{\text {unsteady }}$ & $\begin{array}{l}\text { unsteady dynamic pressure in intermittent } \\
\text { boundary layer }\end{array}$ & $y^{+}$ & $\begin{array}{l}\text { nondimensional normal boundary layer } \\
\text { coordinate, } y^{+}=\frac{y}{x} \operatorname{Re}_{\mathrm{x}} \sqrt{\frac{c_{f}}{2}}\end{array}$ \\
\hline $\operatorname{Re}_{\mathrm{X}}$ & $\begin{array}{l}\text { Reynolds number based on longitudinal } \\
\text { coordinate }\end{array}$ & $y^{+} \operatorname{trans}$ & $\begin{array}{l}\text { normal point of transition between laminar } \\
\text { and turbulent layers }\end{array}$ \\
\hline $\operatorname{Re}_{x_{t r}}$ & transition Reynolds number & $z$ & lateral boundary layer coordinate, $\mathrm{cm}$ \\
\hline$t$ & time & $\alpha$ & angle of attack, deg. \\
\hline$U$ & $\begin{array}{l}\text { time-averaged longitudinal velocity in } \\
\text { boundary layer, } \mathrm{m} / \mathrm{sec}\end{array}$ & $\beta$ & $\begin{array}{l}\text { Clauser nondimensional pressure gradient } \\
\text { parameter }\end{array}$ \\
\hline$U_{e}$ & velocity at edge of boundary layer, $\mathrm{m} / \mathrm{sec}$ & $\gamma$ & intermittency factor \\
\hline$u$ & $\begin{array}{l}\text { longitudinal velocity in boundary layer, } \\
\mathrm{m} / \mathrm{sec}\end{array}$ & $\Delta p$ & differential pressure, $\mathrm{kPa}$ \\
\hline & \multirow[t]{2}{*}{ steady-state velocity ratio } & $\Delta \bar{q}$ & pressure error feedback, $\mathrm{kPa}$ \\
\hline$\left.U_{e}\right\rfloor_{\text {final }}$ & & $\Delta t$ & frame interval, sec \\
\hline & $\begin{array}{l}\text { unsteady perturbation of longitudinal } \\
\text { velocity, } \mathrm{m} / \mathrm{sec}\end{array}$ & $\delta$ & boundary layer thickness, $\mathrm{cm}$ \\
\hline \multirow[t]{3}{*}{$u^{+}$} & \multirow[t]{3}{*}{$\begin{array}{l}\text { nondimensional boundary layer velocity, } \\
u^{+}=\frac{u(y)}{}\end{array}$} & $\delta_{n o i s y}$ & $\begin{array}{l}\text { boundary layer thickness, noisy } \\
\text { simulation, } \mathrm{cm}\end{array}$ \\
\hline & & $\hat{\delta}_{e s t}$ & estimate of boundary layer thickness, $\mathrm{cm}$ \\
\hline & & $\delta^{*}$ & boundary layer displacement thickness, $\mathrm{cm}$ \\
\hline$V$ & $\begin{array}{l}\text { time-averaged normal velocity in boundary } \\
\text { layer, } \mathrm{m} / \mathrm{sec}\end{array}$ & $\delta_{l a m}^{*}$ & $\begin{array}{l}\text { laminar contribution to boundary layer } \\
\text { displacement thickness, } \mathrm{cm}\end{array}$ \\
\hline \multirow[t]{2}{*}{$v^{\prime}$} & \multirow{2}{*}{$\begin{array}{l}\text { normal velocity in boundary layer, } \mathrm{m} / \mathrm{sec} \\
\text { unsteady perturbation of normal velocity, } \\
\mathrm{m} / \mathrm{sec}\end{array}$} & $\delta_{t u r b}^{*}$ & $\begin{array}{l}\text { turbulent contribution to boundary layer } \\
\text { displacement thickness, } \mathrm{cm}\end{array}$ \\
\hline & & $\zeta$ & controller damping ratio \\
\hline$W$ & $\begin{array}{l}\text { time-averaged lateral velocity in boundary } \\
\text { layer, } \mathrm{m} / \mathrm{sec}\end{array}$ & $\eta(t)$ & $\begin{array}{l}\text { uniformly distributed random noise } \\
\text { function }\end{array}$ \\
\hline
\end{tabular}




\begin{tabular}{|c|c|}
\hline$\theta$ & boundary layer momentum thickness, $\mathrm{cm}$ \\
\hline$\theta_{l a m}^{*}$ & $\begin{array}{l}\text { laminar contribution to boundary layer } \\
\text { momentum thickness, } \mathrm{cm}\end{array}$ \\
\hline$\theta_{t u r b}^{*}$ & $\begin{array}{l}\text { turbulent contribution to boundary layer } \\
\text { momentum thickness, } \mathrm{cm}\end{array}$ \\
\hline$\kappa$ & $\begin{array}{l}\text { law of the wake velocity distribution slope } \\
\text { parameter }\end{array}$ \\
\hline$\kappa_{s}$ & surface roughness height, $\mathrm{cm}$ \\
\hline$\kappa^{+}$ & non-dimensional surface roughness, \\
\hline$\lambda$ & dummy variable of integration \\
\hline$\lambda_{\text {trans }}$ & $\begin{array}{l}\text { effective normal height of laminar } \\
\text { sub-layer, } \mathrm{cm}\end{array}$ \\
\hline$\mu$ & mean deviation in $C_{F}$ \\
\hline$\Pi$ & wake parameter \\
\hline$\sigma$ & standard deviation in $C_{F}$ \\
\hline$\omega_{n}$ & controller natural frequency, $\mathrm{sec}^{-1}$ \\
\hline$\frac{\partial p}{\partial x}$ & longitudinal pressure gradient, $\mathrm{kPa} / \mathrm{m}$ \\
\hline$\frac{\partial \theta}{\partial x}$ & longitudinal momentum thickness gradient \\
\hline \multicolumn{2}{|c|}{ Mathematical Operators } \\
\hline$(\dot{)})$ & first derivative with respect to time \\
\hline$(\ddot{)})$ & second derivative with respect to time \\
\hline
\end{tabular}

Lifting body and wing body designs currently advocated for transatmospheric reusable launch vehicles (RLV) or for crew return from the space station are derived from variations on the original lifting body concept. ${ }^{1}$ For a variety of reasons, these designs have large base areas relative to the vehicle size when compared to previous hypersonic designs. For example, on the X-33 and VentureStar ${ }^{\mathrm{TM}}$ (Lockheed Martin, Bethesda, Maryland) configurations the large base areas are required to accommodate aerospike engines. Conversely, the X-38 - derived from the original X-24A mold lines-has a large blunt base area resulting from the upper body flap required to trim the vehicle. In both of the above cases, the base area flow is highly separated resulting in large negative base pressure coefficients. Because of the large base-to-wetted-area ratios of these vehicles, the base drag makes up the majority of the overall vehicle drag. Thus the base drag has a large impact on critical vehicle performance parameters such as maximum payload and maximum cross-range. Any decrease in base drag has the potential to significantly improve the overall vehicle performance. An increase in the vehicle lift-to-drag ratio would allow for a much less severe glide slope during the terminal phase of the vehicle reentry. Reduction in glide-slope steepness would in turn make the terminal area energy management task considerably easier.

\section{Early Work Points to a Possible Solution}

There is a feasible means for decreasing base drag. For blunt-based objects with base areas that feature heavily separated flows, a clear relationship is demonstrated between the base drag and the viscous forebody drag. ${ }^{2,3}$ Figure 1 shows the base drag coefficient plotted against the viscous forebody drag coefficient. The viscous forebody drag coefficient is defined as the sum of all viscosity-induced drag components on the vehicle forebody. These components include skin friction, forebody separation, forebody wakes, and parasite drag due to protuberances. The trend presented in figure 1 shows that as the forebody drag is increased the base drag of the vehicle generally tends to decrease. This base-drag reduction is a result of boundary layer effects at the base of the vehicle. The shear layer caused by the free-stream flow rubbing against the dead, separated air in the base region acts as a "jet pump" 2 and serves to reduce the pressure coefficient in the base areas. The surface boundary layer acts as an insulator between the external flow and the dead air at the base. As the viscous forebody drag is increased, the boundary layer thickness at the aft end of the forebody increases-reducing the effectiveness of the pumping mechanism-and the base drag can potentially be reduced.

\section{Flight Tests on SR-71 LASRE Experiment}

Recent work performed on the Linear Aerospike SR-71 Experiment (LASRE) flight program has demonstrated that the trend presented in figure 1 can be practically applied to reduce the base drag of a large projectile. ${ }^{4}$ In the LASRE experiment, a portion of the forebody of the test model was roughened to increase the forebody drag. A decrease in base drag was observed at all Mach numbers-subsonic, transonic and supersonic.

\section{Trade-Off Between Forebody Drag and Base Drag}

More significantly, figure 1 data show that projectiles with a base drag coefficient greater than 0.30 (referenced to the base area) must necessarily lie on the relatively steep segment of the curve presented. In this 
region a small change in the forebody friction drag should result in a relatively large change in the base drag. Conceptually, if the added change in forebody skin drag is optimized with respect to the base drag, then it may be possible to reduce the overall drag of the configuration. That is, based on Hoerner's data, an optimal drag bucket should exist. Figure 2 shows this optimal drag region. Here the base drag and the total vehicle drag are plotted against the viscous forebody drag including measured data for several hypersonic lifting-body and wing-body configurations: ${ }^{3}$ These are the X-15, M2-F1, M2-F2, Shuttle, HL-10, X-24A, $\mathrm{X}-24 \mathrm{~B}$, and the SR-71 LASRE. The simple model in figure 2 is presented only as an illustration of the dragbucket concept. Clearly, the forebody pressure profile and the presence of induced drag and localized interference or flow separation drag will likely alter the shape of the optimal curve presented in figure 2 . The challenge is to modify the forebody drag coefficient to produce the minimum overall vehicle drag in a realworld configuration.

\section{On the Need for Real-Time Forebody Viscous Drag Measurements}

An intriguing concept for implementing the drag optimization described above utilizes recent advances in microelectromechanical systems (MEMS) ${ }^{\mathbf{5}}$ technology. In this concept MEMS technology is used to adaptively vary the surface roughness in order to track the optimal skin friction. This design uses a "fish-scale" pattern of microscale actuators distributed along the vehicle skin. The position of these microscale surface panels is commanded in real-time to modify the local surface roughness and increase or decrease the total forebody viscous drag coefficient, as required, to achieve the overall drag minimum. This optimization process requires that the viscous forebody drag coefficient be sensed and available for feedback to the MEMS controller in real-time. To be practical for the optimization problem, the forebody drag measurement device must be self-contained; that is, the measurement system must be installed entirely onboard the vehicle. Additionally, the device must be able to adapt to widely varying boundary layer thickness.

None of the existing methods for sensing the surface skin friction are easily adaptable to the above optimization problem. This paper briefly examines why there are limitations with the current skin-friction measurement techniques and then proposes a new method for sensing the viscous forebody drag coefficient based on the law of the wake. ${ }^{6}$ The engineering model developed for this new method allows longitudinally averaged skin-friction measurements to be made in a direct manner with a single measurement of the boundary layer thickness near the aft end of the forebody. For simplicity, all analyses and data presented assume incompressible flow relationships. It is simply a matter of detail to extend these discussions to account for the effects of compressible flow.

Note that use of trade names or names of manufacturers in this document does not constitute an official endorsement of such products or manufacturers, either expressed or implied, by the National Aeronautics and Space Administration.

\section{Background}

This section briefly discusses existing methods for sensing surface skin friction and presents the reasons why these methods are unsatisfactory for our current measurement problem. Current methods for measuring surface skin friction can be grouped into two classes: direct measurements and indirect measurements.

\section{Direct Skin Friction Measurements}

The direct measurement methods sense surface shearing stress by using small floating balances or through the use of surface-imaging interferometry. The balance methods are generally self-contained and have been successfully applied to flight vehicles. ${ }^{7,8}$ Unfortunately, experience has demonstrated that surface-mount skin-friction gauges are also susceptible to damage and thermal shifts, and they require frequent re-calibration to achieve accurate results.

Oil-film interferometry has been used to produce very accurate localized skin-friction measurements; 9 however, these techniques are usually applied only in a laboratory setting. Because they require remote optical imaging of the flow field, interferometry methods are inherently not self-contained and are not easily adapted for use on flying vehicles. The rapid development of fiber-optic sensors may provide a practical method to overcome this problem. Developing these optically sensed skin-shear sensors to be rugged and reliable will be a challenge for some time yet to come.

\section{$\underline{\text { Indirect Skin Friction Measurements }}$}

Two of the most common indirect methods used to compute skin-friction coefficients on flight vehicles are Preston tubes and boundary-layer rakes. Both types of sensors are reasonably easy to fabricate and install, and offer the advantage of being self-contained, reliable, and 
rugged. Unfortunately, both designs have limitations that restrict their real-time applicability and make them generally unsuitable for the drag optimization problem.

Preston Tubes ${ }^{10,11}$ offer a simple hardware solution where a single pitot tube is located as close to the surface as possible. By assuming a log-law velocity profile, $^{12}$ and using measurements of the local wall static and surface pitot pressure, the local skin-friction coefficient can be calculated. These methods have been successfully applied to a large number of flight and wind tunnel tests. However, the drag optimization problem requires that the entire viscous forebody drag coefficient - which includes the effects of skin friction, forebody separation, forebody wakes, and parasite drag due to protuberances - must be sensed. Unfortunately, the log-law velocity distribution is not valid in the outer layers of the boundary layer or within the wake region. Thus it is believed that Preston tubes will not be able to completely capture the range of required forebody drag measurements. It is possible that the Preston tube analyses can be modified to allow for the effects of the outer wake region; however that analysis is beyond the scope of this paper.

Boundary-layer rakes consist of an assembly with multiple pitot probes placed in a normal line away from the skin of the vehicle. Boundary-layer rakes sense the local dynamic pressure profile within the boundary layer and use these data to compute the velocity distribution. This velocity distribution is numerically integrated to produce a measurement of the local momentum thickness. ${ }^{12}$

In order to obtain accurate momentum thickness measurements using a boundary-layer rake, it is critical that the rake be designed to obtain adequate normal resolution within the critical shearing layers near the surface where the momentum defect distribution reaches a peak value. This "hump" in the momentum thickness curve occurs near the interface of the laminar sublayer with the outer turbulent log-law velocity distribution layer. This resolution requirement means that a large number of measurements, typically 6-10 probes, must be made in order to sense the velocity profile with a sufficient amount of resolution. This large amount of data must be sampled and integrated in real time. Additionally, the frame-by-frame results must be heavily post-processed to eliminate the effects of local boundary noise. While these limitations certainly do not preclude the use of boundary-layer rakes for real-time forebody drag measurements, it is believed that these results can be achieved by a more straightforward measurement technique.

\section{A New Measurement Approach}

The real-time measurement technique being developed in this paper exploits design features of both Preston tubes and boundary-layer rakes. In this approach a reference pitot probe is inserted into the flow, well above the maximum anticipated thickness of the local boundary layer. Another pitot probe is mounted on a servomechanism which moves in a direction normal to the surface. A controller regulates the position of the servomechanism based on the measured pressure difference between the moving pitot probe and the reference pitot probe. This design concept is pictured schematically in figure 3 . The design will be tailored to typically allow the probe to track the area within the outer wake region near the edge of the boundary layer. A position sensor on the probe gives a measure of the local boundary layer thickness. This probe position is related to the forebody skin-friction coefficient using a law-of-wake analysis. This analysis is presented in the next section. The crux of this analysis is the development of an integral relationship that describes the skin-friction coefficient in terms of a local measurement of the boundary layer thickness.

\section{Integral Law of the Wake Analysis}

The key to the floating-probe concept described in the previous section is Coles' law of the wake. ${ }^{6}$ The law of the wake relates the outer (turbulent) boundary-layer variables to the nondimensionalized boundary-layer coordinates

$$
u^{+}=\frac{1}{\kappa}\left[\ln \left[y^{+}\right]+2 \Pi \sin ^{2}\left[\frac{\pi}{2} \frac{y}{\delta}\right]\right]+B
$$

where,

$$
u^{+}=\frac{u(y)}{U_{e \sqrt{\frac{c_{f}}{2}}}}, y^{+}=\frac{y}{x} \operatorname{Re}_{\mathrm{x}} \sqrt{\frac{c_{f}}{2}}
$$

$\delta$ is the local boundary-layer thickness, $\kappa$ is the slope parameter, $B$ is a bias parameter, $\Pi$ is the wake parameter, ${ }^{13}$ and $C_{F}$ is the local viscous forebody drag coefficient. The currently accepted "best value" for $\kappa$ is approximately 0.41 . The bias parameter, $B$, varies with the level of surface roughness and for a smooth plate has a numerical value of approximately 5.0. The wake parameter is proportional to the local longitudinal pressure gradient, and for a zero-gradient flow condition this wake parameter has a numerical value of approximately 0.55 . The roughness-dependent bias term 
can be eliminated from equation 1 by expressing the law of the wake in terms of the local velocity defect.

$$
\begin{gathered}
{\left[1-\frac{u(y)}{U_{e}}\right]=\sqrt{\frac{c_{f}}{2}} \frac{1}{\kappa}\left(\left[2 \Pi \cos 2\left[\frac{\pi}{2} \frac{y}{\delta}\right]-\ln \left[\frac{y}{\delta}\right]\right] \approx\right)} \\
\sqrt{\frac{c_{f}}{2}}\left[4.878 \Pi \cos 2\left[\frac{\pi}{2} \frac{y}{\delta}\right]-2.439 \ln \left[\frac{y}{\delta}\right]\right]
\end{gathered}
$$

General Solution Method for Local Skin-Friction Coefficient

As developed in Appendix A, equation 3 is integrated across the depth of the boundary layer, including the laminar sublayer, to relate the momentum and displacement thickness to the local boundary thickness and the local pressure gradient. The resulting relationships are (1) momentum thickness and (2) displacement thickness.

(1) Momentum thickness:

$\frac{\delta}{x} \sqrt{{ }^{c_{f}}}\left[\begin{array}{c}{[0.16425+2.66116 \sqrt{0.88881+\beta}]-} \\ {[10.4874+10.6227 \beta+2.13276 \sqrt{0.88881+\beta}] \sqrt{{ }^{c} f}}\end{array}\right]$ $+\frac{55.9194-40.6563 \sqrt{0.88881+\beta}}{\operatorname{Re}_{X}}$

$+\frac{\sqrt{c_{f}}[-137.422+162.4 \beta+32.6051 \sqrt{0.88881+\beta}]}{\operatorname{Re}_{\mathrm{x}}}$

(2) Displacement thickness:

$$
\begin{gathered}
\frac{\delta^{*}}{x}=\frac{\delta}{x} \sqrt{c_{f}}[[0.16425+2.66116 \sqrt{0.88881+\beta}]] \\
+\frac{55.9194-40.6563 \sqrt{0.88881+\beta}}{\operatorname{Re}_{x}}+
\end{gathered}
$$

In equations $4(a)$ and $4(b), \beta$ is the Clauser parameter, ${ }^{13}$ and is related to the local pressure gradient by

$$
\beta \equiv \frac{\delta}{c_{f}} \frac{\partial p}{\frac{\partial x}{\bar{q}}}
$$

Clearly negative values of $\beta$ correspond to favorable pressure gradients and positive values of $\beta$ correspond to adverse pressure gradients. A pressure gradient with $|\beta|<0.1$ is considered to be a weak, and a pressure gradients with $|\beta|>0.1$ is considered to be strong. White ${ }^{14}$ develops a similar set of integral relationships for the momentum and displacement thickness, but does not include the effect of the laminar sublayer.

Closure is added to the problem by applying the correlation equation developed by White, ${ }^{14}$

$$
c_{f}=\frac{0.3 \mathrm{e}^{-1.33 \delta^{*} / \theta}}{\left[\log _{10} \operatorname{Re}_{\mathrm{x}} \frac{\theta}{x}\right]^{1.74+0.31 \delta^{*} / \theta}}
$$

Equations 4, 5, and 6 can be used to solve for the entire state of the local boundary in terms of the normalized boundary-layer thickness, Reynolds number, and the Clauser pressure gradient parameter. Parameters which are estimated include the local skinfriction coefficient, momentum thickness, displacement thickness, and the boundary-layer shape parameter $\left(\delta^{*} / \theta\right)$. This system of equations is extremely nonlinear but is reasonably well-behaved and is numerically solved using a simple substitution iteration procedure. Unfortunately, the correlation of equation 6 was developed from smooth surface data only. Thus this solution procedure should be applied to smooth surfaces only. For the remainder of this paper, this iterative solution procedure will be referred to as the nonlinear method.

\section{Zero Pressure Gradient Solution for Longitudinally Averaged Skin-Friction Coefficient}

If the local pressure gradient is small or negligible $(\beta \sim 0)$, then the longitudinally averaged forebody viscous drag coefficient is directly related to the local momentum thickness using the integral form of the Von Karman momentum equation

$$
\frac{\theta}{x}=\frac{1}{x} \int_{0}^{x^{c}} \frac{f}{2} d x=\frac{{ }^{c} f}{2}
$$

Substituting equation 7 into equation $4(a)$ and evaluating for $\beta=0$, an expression for the longitudinally averaged viscous drag coefficient in terms of the local skin-friction coefficient is derived

$$
\begin{aligned}
C_{F}= & \frac{\delta}{x} \sqrt{c_{f}}\left[5.3464-24.998 \sqrt{c_{f}}\right] \\
& +\frac{1}{\operatorname{Re}_{\mathrm{x}}}\left[35.12-213.342 \sqrt{c_{f}}\right]
\end{aligned}
$$


In equation $8(a), C_{F}$ is the longitudinally averaged viscous drag coefficient. Evaluating equation 1 at $y=\delta$ gives an implicit formula for the local skinfriction coefficient in terms of the $\delta$ and $\operatorname{Re}_{\mathrm{X}}$

$$
\sqrt{\frac{2}{c_{f}}}=2.439\left[\ln \left[\sqrt{\frac{c_{f}}{2}} \frac{\delta}{x} \operatorname{Re}_{\mathrm{x}}\right]+2 \Pi\right]+B
$$

As mentioned earlier, for a smooth surface $\beta=5.0$. For rough surfaces, White ${ }^{14}$ has curve-fit the Prandtl-Schlicting sand grain roughness curve to obtain the following formula

$$
\mathrm{B}=5.0-2.439 \ln \left[1+0.30 \kappa^{+}\right]
$$

In equation $9, \kappa^{+}$is the nondimensional surface roughness and is defined as

$$
\kappa^{+}=\frac{\kappa_{s}}{x} \operatorname{Re}_{\mathrm{x} \sqrt{\frac{c_{f}}{2}}}
$$

A surface is defined as "rough" when $\kappa^{+}>5.0$. For $\kappa^{+}<5.0$, the surface is said to be "hydraulically smooth." Equation 9 is valid for turbulent flow conditions that are smooth, transitionally rough (only part of the surface is rough), and fully rough (the entire surface is rough). Collectively, equations 8,9 , and 10 offer a nonlinear set of equations which can be used to solve for the longitudinally averaged viscous drag coefficient in terms of the local boundary-layer thickness, Reynolds number, and the surface roughness ratio. This set of equations is well-behaved and can be solved iteratively using a simple substitution method. Since the local skin-friction coefficient is computed by evaluating the law of the wake at the edge of the boundary layer for the remainder of this paper, this solution method is referred to as the edge method.
Closed-Form Solution Method for Averaged Skin-

\section{Friction Coefficient}

When the entire surface is rough (a fully rough flow regime), experimental observations show that the ratio of the local and averaged skin-friction coefficients is a function of only the normalized surface roughness, $\left(x / \kappa_{s}\right)$. For a fully rough flat plate Mills, ${ }^{15}$ et. al. have developed the following relationship for the skinfriction ratio

$$
\frac{c_{f}}{C_{F}}=G\left[\frac{x}{\kappa_{s}}\right]=\frac{\left[2.635+0.618 \ln \left[\frac{x}{\kappa_{s}}\right]\right]^{2.57}}{\left[3.476+0.707 \ln \left[\frac{x}{\kappa_{s}}\right]\right]^{2.46}}
$$

Equation 11 is valid over a Reynolds number range from approximately $10^{5}$ to $10^{8}$. For large Reynolds numbers $\left(\operatorname{Re}_{\mathrm{x}}>10^{7}\right)$ an approximate skin-friction ratio for fully developed turbulent flow on a hydraulically smooth plate is derived by setting the roughness ratio to a very large value. Evaluating equation 11 at $x / \kappa_{s}=10^{8}$, gives $G\left[x / \kappa_{s}\right] \sim 0.896$.

By substituting $G[x]$ into equation $8(a)$ and simplifying, the solution for the averaged viscous drag coefficient are written in closed form

Equation 12 gives the relationship between the local boundary layer thickness and the averaged surface skinfriction coefficient. This simple result is important because it requires only a single measurement of the boundary layer thickness and an estimate of the Reynolds number and surface-roughness ratio to determine the local momentum defect. When the pressure gradients are small, the local momentum defect is a good approximation of the averaged skin friction. Data to be presented in the Results and Discussion

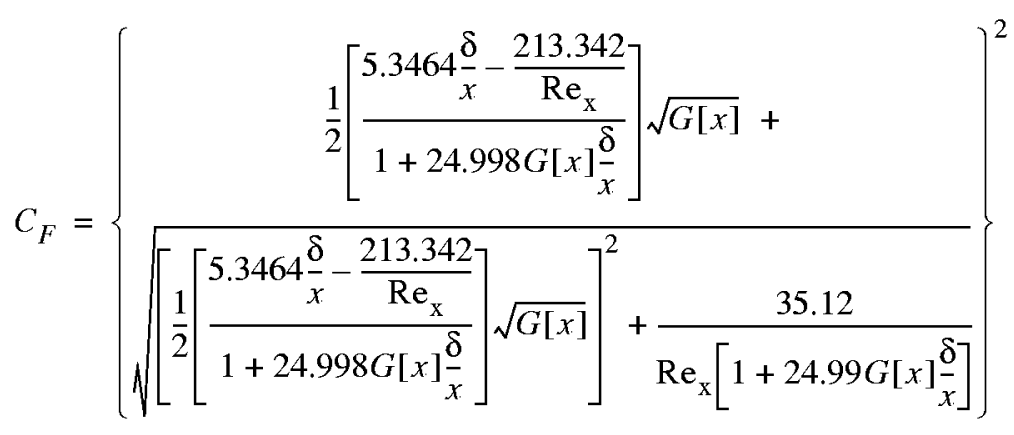


section demonstrate that the closed-form model gives results that are accurate to within 5 percent as long as $|\beta|<0.1$. This accuracy estimate holds for fully rough surfaces with turbulent flow and for hydraulically smooth surfaces with turbulent flow occurring at the leading edge. For the remainder of this paper equation 12 is referred to as the closed-form solution.

Calculations from the various solutions methods are compared in the Results and Discussion section. These comparisons help in determining the regions of applicability for the solution methods.

\section{Design of the Boundary Layer Tracking Probe}

As mentioned earlier the integral form of the law of the wake-where the skin-friction coefficient is expressed in terms of the local boundary layer thickness -suggests an innovative concept for a skin-friction measurement device. While the actual mechanical design of the probe can vary substantially, the basic concept is that a reference pitot probe is inserted into the flow, well above the maximum anticipated thickness of the local boundary layer. Another pitot probe is servomechanism-driven to move normally to the surface. A controller regulates the position of the floating probe. As developed in Appendix B the continuous-time control law for this system is

$$
\ddot{y}+2 \zeta \omega_{n} \dot{y}+\omega_{n}^{2} \frac{n}{2} y=\omega_{n}^{2} \frac{n}{2}\left[\frac{y}{\bar{q}}\right] \Delta \bar{q}
$$

In equation $13, y$ is the probe position measured relative the to the surface, $\bar{q}$ is the local dynamic pressure at position $\mathrm{y}$ within the boundary layer, and $\Delta \bar{q}$ is the difference between the dynamic pressure at the edge of the boundary layer and the local dynamic pressure. Choosing the natural frequency $\left(\omega_{n}\right)$ and damping ratio $(\zeta)$ so that the open-loop system eigenvalues are stable, causes the unforced probe position to always decay to zero. The decaying tendency of the open-loop system insures that the measurementprobe will not remain stuck outside of the boundary layer where the pressure difference between the reference and measurement-probes is zero. The analog flow diagram for this control equation is depicted in figure 4 .

\section{Discrete Control Law}

Equation 13 is discretized using the trapezoidal ${ }^{16}$ rule. After performing some extensive algebra, the discrete control equation is written as

$$
y_{k+1}=\frac{A_{k}}{C_{k}} y_{k}-\frac{B_{k}}{C_{k}} y_{k-1}
$$

Where the coefficients of equation 14(a) are

$$
\begin{aligned}
& A_{k}=2\left\{\left[1-\left(\omega_{n} \frac{\Delta t}{2}\right)^{2}\left[1-\frac{n}{2}\left[\frac{[\Delta \bar{q}]}{\bar{q}}\right]_{k}\right]\right]\right\} \\
& B_{k}=\left(1-2 \zeta \omega_{n} \frac{\Delta t}{2}+\left(\omega_{n} \frac{\Delta t}{2}\right)^{2}\left[1-\frac{n}{2}\left[\frac{[\Delta \bar{q}]}{\bar{q}}\right]_{k}\right]\right) \\
& C_{k}=\left(1+2 \zeta \omega_{n} \frac{\Delta t}{2}+\left(\omega_{n} \frac{\Delta t}{2}\right)^{2}\left[1-\frac{n}{2}\left[\frac{[\Delta \bar{q}]}{\bar{q}}\right]_{k}\right]\right)
\end{aligned}
$$

In equation $14 k$ is the time-frame index and $\Delta t$ is the time interval between each frame. These equations can be implemented recursively starting with the initial position of the tracking probe. Since the measured dynamic pressure difference is a function of the local position within the boundary layer, this control law is clearly nonlinear. As such, it is expected that the control law behavior will differ somewhat from the response of a linear second-order system. Clearly though, $n$ is the control gain parameter. An example probe control-law response for an unsteady boundary layer will be presented in the Results and Discussion section.

\section{Final Probe Position}

When the probe is positioned within the boundary layer so that

$$
1-\frac{n}{2}\left[\frac{[\Delta \bar{q}]}{\bar{q}}\right]_{k}=0
$$

equation 14 is rewritten as

$$
y_{k+1}-y_{k}=\left[\frac{1-2 \zeta \omega_{\mathrm{n}} \frac{\Delta t}{2}}{1+2 \zeta \omega_{\mathrm{n}} \frac{\Delta t}{2}}\right]\left[y_{k}-y_{k-1}\right]
$$

Since $\zeta, \omega_{n}$, and $\delta t$ are all positive constants, equation 16 implies that

$$
\left|y_{k+1}-y_{k}\right| \leq\left|y_{k}-y_{k-1}\right|
$$

Thus the difference equations converge to a steady value. As a result the probe seeks a final position where

$$
\left[\frac{\Delta \bar{q}}{\bar{q}}\right]_{\text {final }}=\frac{2}{n}
$$


Equation 18 is written in terms of the final velocity ratio as

$$
\left[\frac{u}{U_{e}}\right]_{\text {final }}=\sqrt{\left[\frac{\bar{q}}{\bar{q}_{e}}\right]_{\text {final }}}=\sqrt{\frac{n}{n+2}}
$$

Equation 19 is used to correct the final probe position by giving the proper estimate of the boundary layer height, assuming that the velocity profile in the outer layers of the boundary layer are approximated by a power-law function. The resulting correction factor is

$$
\hat{\delta}_{e s t}=y_{\text {final }}\left[\frac{n+2}{n}\right]^{m / 2}
$$

In equation 20 the parameter $m$ is the velocity profile exponent and is the function of the local Reynolds number. Values for $m$, which are required to perform the correction of equation 20, are presented in the Results and Discussion section. Once the final probe position has been achieved; the boundary layer thickness estimated by equation 20 is used to evaluate the local and averaged skin-friction coefficients using whichever of the three solutions methods (developed earlier) is appropriate.

\section{$\underline{\text { Results and Discussion }}$}

This section is divided into two parts: a Model Validation section and a Probe Response section. In the Model Validation section the three solution methods for the law of the wake model are compared. These comparisons establish the errors that pressure gradients cause in the edge and closed-form solution methods. Next the closed-form solution is compared to the edge solution for a variety of surface roughness. Finally, skin friction coefficients and velocity profiles predicted by the law-of-the-wake model are compared to flightobtained boundary layer measurements. In the Probe Response section an example of dynamic response of the probe control law for a noisy boundary layer is presented.

\section{Model Validation}

First an estimate of errors in the edge and closed-form solution methods caused by longitudinal pressure gradients are examined. These results are presented in figure 5 . In figure 5 the top graph shows the local skinfriction coefficient predicted by the nonlinear model as a function of Reynolds number. The curves correspond to values of $\beta=\{-0.25,0.0,0.25$, and 1.0$\}$. The solutions for the edge and closed-form methods $(\beta=0$ implicit) are also plotted. For the closed-form solution the "smooth-plate" value of $G\left[x / \kappa_{s}\right]=0.896$ was used. For $\beta=0$ the nonlinear and edge solution methods give nearly identical results. The closed-form solution shows approximately a 2-percent error at $\operatorname{Re}_{x}=10^{6}$. This error diminishes to nearly zero at $\operatorname{Re}_{x}=10^{8}$. The bottom graph in figure 5 shows the percent deviation in the closed-form model, defined by

percent of deviation $=100 \times \frac{c_{f_{\text {nonlinear }}}-c_{f_{\text {closedform }}}}{c_{f_{\text {nonlinear }}}}$ (21)

This parameter is plotted as a function of Reynolds number for values of $\beta=\{-0.25,0.0,0.25$, and 1.0$\}$. The calculated deviations in the edge method are smaller than those shown in the figure 5 bottom graph by approximately 1 percent. These data are not shown. The deviations shown in this bottom graph of figure 5 are also representative of the errors that are expected for the averaged skin friction values. Clearly, there is error introduced by the simplifying assumptions used in deriving the closed-form model. However, if the local pressure gradient is small $(|\beta|<0.10)$, the errors are less than 5 percent over a very wide range of Reynolds numbers.

The simplifying assumption was introduced into the closed-form model by the simplifying assumption of equation 11 . However, as shown in figure 5, this error is less than 2 percent over a wide Reynolds number range for a hydraulically smooth surface. Figure 6 shows how this error varies as a function of surface roughness. The figure 6 top graph compares the edge solution for averaged skin-friction coefficient to the closed-form averaged skin-friction coefficient. The data presented on this curve were computed for a Reynolds number of $5.0 \times 10^{7}$ with roughness levels varying from a very smooth surface to a very rough surface. Also plotted on this figure 6 top graph is the transitionally rough skin friction roughness formula derived by White. ${ }^{14}$ The level of agreement is very close. The bottom graph of figure 6 shows the percent deviation plots (where the edge solution is assumed to be the "truth set"). The deviations are all within 2.5 percent, even at the low Reynolds numbers. As the Reynolds number and surface roughness increase, the deviations diminish to approximately zero.

\section{Comparisons to Flight Data}

Figures 5 and 6 show data in the absence of significant longitudinal surface pressure gradients. In these two figures the closed-form model predicts the 
averaged skin friction to within 5 percent when compared to the more complex iterative solution methods. This result justifies using the simple model of equation 12 for the real-time measurement system. Further justification is evident in comparing averaged skin friction predictions of the closed-form model against data obtained from two flight experiments conducted by Saltzman and Fisher. ${ }^{17,18}$ During these series of tests, both supersonic and subsonic data were obtained; however, since this analysis is currently applied only for incompressible flow conditions, only the subsonic flight data were analyzed. In these flight experiments, boundary-layer rake measurements were obtained on the underside to the fuselage of an A-5A aircraft, and on the wing of the XB-70-1 aircraft. For both series of flight tests a calibrated Preston tube was also installed near the rake to supply additional measurements of the local skin-friction coefficients. Figure 7 shows the A-5A instrument locations and figure 8 shows the XB-70-1 rake and Preston tube locations. Table 1 summarizes the data points that were analyzed.

Table 1. Summary of subsonic flight data analyzed.

\begin{tabular}{cccccc}
\hline \hline $\begin{array}{c}\text { Data } \\
\text { point }\end{array}$ & Vehicle & $\operatorname{Re}_{\mathrm{x}}$ & $\alpha, \mathrm{deg}$ & $M_{\text {edge }}$ & $x, \mathrm{~cm}$ \\
\hline 1 & A5A & $1.54 \mathrm{e}+7$ & 6.2 & 0.82 & 508.0 \\
2 & A5A & $2.20 \mathrm{e}+7$ & 3.8 & 0.64 & 508.0 \\
3 & A5A & $3.00 \mathrm{e}+7$ & 6.4 & 0.60 & 508.0 \\
4 & A5A & $3.11 \mathrm{e}+7$ & 7.0 & 0.51 & 508.0 \\
5 & A5A & $4.94 \mathrm{e}+7$ & 3.2 & 0.81 & 508.0 \\
6 & A5A & $7.42 \mathrm{e}+7$ & 0.3 & 0.81 & 736.0 \\
7 & XB-70-1 & $1.14 \mathrm{e}+8$ & 8.7 & 0.41 & 1557.5 \\
8 & XB-70-1 & $1.18 \mathrm{e}+8$ & 8.1 & 0.49 & 1557.5 \\
9 & XB-70-1 & $1.24 \mathrm{e}+8$ & 8.2 & 0.46 & 1557.5 \\
10 & XB-70-1 & $1.30 \mathrm{e}+8$ & 8.9 & 0.53 & 1557.5 \\
11 & XB-70-1 & $1.33 \mathrm{e}+8$ & 8.3 & 0.51 & 1557.5 \\
12 & XB-70-1 & $1.41 \mathrm{e}+8$ & 5.5 & 0.94 & 1557.5 \\
13 & XB-70-1 & $1.57 \mathrm{e}+8$ & 5.2 & 0.95 & 1557.5 \\
14 & XB-70-1 & $1.73 \mathrm{e}+8$ & 5.7 & 0.91 & 1557.5 \\
\hline \hline
\end{tabular}

For the A-5A tests, all of the data points analyzed were at angles of attack greater than $3.8^{\circ}$, except point number 6 for which the angle of attack was $0.3^{\circ}$. Because the boundary-layer rake for these tests was located on the bottom of the vehicle, for the higher angles of attack (points 1-5) the effect of the noseboom on the Reynolds number was ignored. For these points a total run length of $508 \mathrm{~cm}$ was used. For the low angleof-attack data point (point 6) the effect of the noseboom became significant and a run length of $736 \mathrm{~cm}$ was used. For the XB-70-1 tests the run length was approximately $1557.5 \mathrm{~cm}$.

For each data point the boundary layer thickness was obtained by fitting the data with a $1 / \mathrm{m}^{\text {th }}$ power law

$$
\ln y=\ln \delta+m \ln \left[\frac{u}{U_{e}} / 0.99\right]
$$

Figure 9 shows an example linear-log plot for data point number $2(\mathrm{~A}-5 \mathrm{~A})$ in table 1 . The $y$-intercept value is 1.8112 and the boundary layer thickness is approximately $\delta \approx \mathrm{e}^{1.8112}=6.118 \mathrm{~cm}$. The linear-log slope represents the power law exponent, hence $m \approx 7.9613$. Based on this "measured" boundary layer thickness, the closed-form solution was used to compute both the averaged and local skin-friction coefficients. These data were then used with equation 3 to compute the velocity profile and momentum distribution within the boundary layer. Figure 10 shows the velocity and momentum profile comparisons for data point 2 (A-5A, $\left.\operatorname{Re}_{\mathrm{X}}=2.20 \times 10^{7}\right)$. Outside of the laminar sublayer, the comparisons are excellent. Similar velocity and momentum distribution profiles are presented in figure 11 for data point $10\left(\mathrm{XB}-70-1, \mathrm{Re}_{\mathrm{x}}=13.0 \times 10^{7}\right)$. The comparisons are very similar to those in figure 10 . The characteristics of these selected data points are very similar to all of the data points which were examined.

Figure 12 summarizes the flight data analysis. Figure 12 plots the law of the wake (averaged) skinfriction (closed-form solution) coefficients calculated using flight-measured boundary layer thickness against previously published ${ }^{17,18}$ values determined by the authors. The published data include local skin friction estimates determined from the rake data using an adaptation of the Clauser method. ${ }^{13}$ Flight-measured Preston tube data are also shown. The Preston tube data were analyzed using the log-law calibration method of Hopkins and Keener. ${ }^{10}$ The published data were expressed in terms of the local skin-friction coefficients and must be transformed to averaged values for the comparisons to be valid. The local skin friction data were transformed to averaged values using the method of Mills. ${ }^{15}$ In this method the skin friction ratio is derived from integrating the local skin friction from the leading edge of the forebody along a flow streamline to the local position. The effect of laminar flow near the leading edge is accounted for. The result is 


$$
\begin{aligned}
\frac{C_{F}}{c_{f}}= & \frac{2.9187}{\sqrt{\operatorname{Re}_{\mathrm{x}_{\mathrm{tr}}}}} \ln { }^{2}\left[0.06 \mathrm{Re}_{\mathrm{x}}\right]\left[\frac{\operatorname{Re}_{\mathrm{x}_{\mathrm{tr}}}}{\operatorname{Re}_{\mathrm{x}}}\right] \\
& +1.1495\left[1-\frac{\operatorname{Re}_{\mathrm{x}}}{\operatorname{Re}_{\mathrm{x}_{\mathrm{tr}}}} \frac{\ln { }^{2}\left[0.06 \mathrm{Re}_{\mathrm{x}}\right]}{\ln ^{2}\left[0.06 \mathrm{Re}_{\mathrm{x}_{\mathrm{tr}}}\right]}\right]
\end{aligned}
$$

In equation $23 \operatorname{Re}_{x_{t r}}$ is the transition Reynolds number and $\operatorname{Re}_{\mathrm{x}}$ is the local Reynolds number. For this transformation a transition Reynolds number of approximately $5.0 \times 10^{5}$ was assumed.

Figure 12 shows the skin-friction coefficients plotted against the normalized boundary layer height. The (adjusted) published data generally scatter about the law-of-the-wake curve; however the scatter is large. Table 2 summarizes the mean and standard deviations of the adjusted rake and Preston tube $C_{F}$ values away from the law of the wake determined values.

Table 2. Deviations of flight measured $C_{F}$ from law of the wake.

\begin{tabular}{cccccc}
\hline \hline & \multicolumn{2}{c}{ Rake } & & \multicolumn{2}{c}{ Preston tube } \\
\cline { 2 - 3 } \cline { 5 - 6 } & $\begin{array}{c}\mu, \\
\text { percent }\end{array}$ & $\begin{array}{c}\sigma, \\
\text { percent }\end{array}$ & & $\begin{array}{c}\mu, \\
\text { percent }\end{array}$ & $\begin{array}{c}\sigma, \\
\text { percent }\end{array}$ \\
\hline A-5A & 10.68 & 31.0 & & 1.2 & 27.0 \\
XB-70-1 & -5.9 & 11.7 & & -5.3 & 10.7 \\
\hline \hline
\end{tabular}

The XB-70-1 data show a much better agreement than do the A-5A data. The reasons for the large amount of scatter in the A-5A data are unclear. Because the test array was located on the underside of the vehicle fuselage, it is possible that angle-of-attack effects induced strong local pressure gradients which had a significant influence on the local skin friction measurements. The 5- to 10-percent mean deviations are not, however, unreasonable.

\section{Simulation of the Boundary-Layer Tracking Probe} Response

The previous section established that the integral lawof-the-wake analysis is a reasonably accurate predictor (within 5 to 10 percent) of the average skin-friction coefficient in the absence of large external pressure gradients. For real-time applications the closed-form solution given by equation 12 is the preferred solution method. The value of the closed-form solution is that the averaged skin-friction coefficient can be incorporated in calculations directly by simply measuring the local boundary layer thickness. This section analyzes the dynamics of the tracking device that is used to obtain the boundary layer thickness measurement. In this section the performance of the tracking probe is modeled using both steady-state and noisy boundary layer simulations.

\section{Effects of the Control Gain Parameter}

In this series of simulations the boundary layer thickness and the velocity profile are assumed to be constant as a function of time. The probe is released at time $t=0$ with a starting value of $y / \delta=0.25$. To match the expected transonic Reynolds numbers that atmospheric reusable launch vehicles encounter, the Reynolds number was held constant at $\operatorname{Re}_{\mathrm{x}}=5.0 \times 10^{7}$. The simulations were all run at 250 samples per second. Figure 13 demonstrates the effect of the control gain parameter $(n)$ on the system response. Here the simulation is run with the natural frequency, damping ratio, and Reynolds number fixed at $\omega_{n}=4 \pi \sec ^{-1}, \zeta=0.7071$, and $\operatorname{Re}_{\mathrm{x}}=5.0 \times 10^{7}$. The control gain parameter is varied from 10 to 500 . The results illustrate an interesting point regarding the trade-off between final position of the probe and the oscillatory stiffness of the model response. As predicted by equation 19 , when the gain is increased, the final position of the probe is closer to the boundary layer edge. Unfortunately, high gain values induce an undesirable response in the system, and the probe never settles down to a stable value. Clearly, it is preferable to allow the probe to track at some fraction of the boundary layer height, and correct the final position using equation 20. It is recommended that values of $n$ be kept somewhere within the range from 20 to 50 .

\section{Correction for the Final Probe Position}

The velocity profile exponent $(m)$, which was required to correct the final probe position and estimate the true boundary layer thickness, was determined by running a series of simulations in which the Reynolds number and gain parameter were allowed to vary. These results are presented in figure 14. Figure 14 shows the variation of $m$ with Reynolds number for control gains of 10,20,50, 100 , and 200 . The data of figure 14 were fit with a simple linear model of the form

$$
m\left[n, \operatorname{Re}_{\mathrm{x}}\right]=C_{0}[n]+C_{1}[n] \log { }_{10}\left[\operatorname{Re}_{\mathrm{x}}\right]
$$


The coefficients of equation 24 are displayed in Table 3.

Table 3. Velocity profile exponent: fit coefficients.

\begin{tabular}{rcc}
\hline \hline$n$ & $C_{0}$ & $C_{1}$ \\
\hline 10 & -0.51785 & 0.95893 \\
20 & 0.11626 & 0.96786 \\
50 & 0.69694 & 1.06950 \\
100 & 1.29530 & 1.14760 \\
200 & 1.89040 & 1.24180 \\
\hline \hline
\end{tabular}

Linear interpolations of the coefficients in Table 2, as a function of $n$, are used to obtain a correction function for the final probe position.

\section{Tracking an Unsteady Boundary Laver}

The steady-state analyses of the previous section were extremely useful in understanding the dynamics of the tracking probe control law; however, a true boundary layer is not at all stationary. In reality a turbulent boundary layer has random elements and instantaneous variations that can only be statistically predicted. The result is an intermittent boundary layer with a ragged shape. In the outer regions of the boundary layer there are turbulent fluctuations which extend beyond the normally defined boundary layer edge. Conversely, there are intermittent regions inside of the normally defined boundary layer where the velocity is equal to the free-stream velocity. The law-of-the-wake analysis presented in this paper deals only with the timeaveraged velocity components of the boundary layer. However, the dynamic flow components will effect the performance of the boundary layer tracking probe and this flow intermittency must be modeled in the probe simulation. In this paper the random components within the boundary layer are modeled using data taken from Klebanoff. $^{19}$ This intermittent boundary-layer model is developed in detail in Appendix B.

The response of the probe to an intermittent boundary layer will now be presented. Reynolds number was set at $\operatorname{Re}_{\mathrm{x}}=5.0 \times 10^{7}$, and the natural frequency, damping ratio, and control gain parameter were varied to determine the best combinations required in order to accurately track the edge of the boundary layer. Using the corrected probe position, the skin-friction coefficient is computed using equation 12 . Figure 15 presents the results of a noisy simulation run with a very stiff control law. In this simulation the parameters were set at $\omega_{n}=\pi / 2 \mathrm{sec}^{-1}, \zeta=0.7071$, and $n=25$. The response of the tracking probe and the corrected probe position are shown relative to the normalized boundary layer edge in figure 15(a). The estimated skin-friction coefficient calculated using equation 12 is shown compared to the known value in figure $15(\mathrm{~b})$. The probe position correction based on equation 25 works quite well and the estimated skin-friction coefficient tracks within 5 percent of the "truth value"-once the initial startup transient has died out. This simulation is presented for illustrative purposes only. The particular values which are preferred for the control law parameters must be tuned to the test conditions, hardware characteristics, desired probe response time, and noise rejection characteristics. Clearly more work needs to be performed in this area.

\section{$\underline{\text { Summary and Concluding Remarks }}$}

Lifting body and wing body designs currently advocated for transatmospheric reusable launch vehicles are derived from variations on the original lifting body concept. These designs have large base areas relative to the vehicle wetted area. Thus the base drag has a large impact on critical vehicle performance parameters such as maximum payload and maximum cross-range. Any decrease in base drag can have the potential to significantly improve the overall vehicle performance. Recent work has demonstrated that by increasing the forebody drag of these vehicle shapes it may be feasible to reduce the base drag so significantly, that the overall drag of the vehicle can be reduced. Methods for optimizing this drag reduction process are currently being studied.

Any attempt to implement the drag optimization requires a practical method for measuring the viscous forebody drag of the vehicle in real time. To be practical for the optimization problem, skin friction measurements must be self-contained, that is, they must be installed onboard the vehicle entirely. As discussed, none of the existing methods for sensing the surface skin friction are readily adaptable to the above optimization problem.

This paper proposes a new method based on the law of the wake. In this concept a reference pitot probe is inserted into the flow, well above the anticipated maximum thickness of the local boundary layer. Another probe is servomechanism-driven and floats within the boundary layer. A controller regulates position of the floating probe. The measured servomechanism-position gives a direct measurement of the local boundary layer height. The measured boundary 
layer height is related to the local and longitudinally averaged skin friction by an integral form of the law of the wake.

In the law-of-the-wake analysis the turbulent boundary layer velocity profile equations were numerically integrated across the boundary layer depth to develop an engineering model that relates longitudinally averaged skin-friction coefficients to local boundary layer thickness. The law-of-the-wake analysis develops three solution methods: 1) an iterative nonlinear solution, 2) an edge solution where the local skin friction is evaluated from the law of the wake at the edge of the boundary layer, and 3) a less-general closedform solution. The non-linear solution method solves for the local skin friction coefficient, momentum thickness, displacement thickness, and the boundary layer shape parameter. The nonlinear solution method is generally applicable to smooth surfaces with arbitrary longitudinal pressure gradients, but does not allow the averaged skin-friction coefficient to be evaluated. The edge method is valid only when the pressure gradients are small, but allows both the local and averaged skinfriction coefficients to be solved for. The edge method is valid for smooth, transitionally rough, and fully rough surfaces. The closed-form solution method is the least general of the three solution methods and is applicable only for fully rough surfaces when the pressure gradient is small. The closed-form solution offers the clear advantage of being an explicit solution; whereas, the first two methods require an iterative calculation. For real-time applications, as long as the flow constraints are not violated, the closed-form method is clearly the preferable choice.

Comparisons of the closed-form solution method to flight data show that the velocity longitudinally averaged skin friction can be sensed with reasonable accuracy. The flight data show that it is clearly possible to achieve mean accuracies on the order of 5 to 10 percent. Applying corrections for the longitudinal pressure gradient and the effects of compressibility can likely reduce these errors further.

The dynamics of the tracking device used to obtain the boundary layer thickness measurement were presented. The performance of the tracking probe was modeled using both steady-state and noisy boundary layer simulations. Simulation results showing performance of the boundary layer tracking probe for a noisy boundary layer were presented. The particular values that are preferred for the control law parameters must be tuned to the test conditions to obtain the desired probe response time and noise rejection by the probe control law.

To be more generally applicable, additional comparisons of the integral law of the wake to transonic and supersonic flight data should be performed. If possible, a compressibility correction must be developed. Additional data comparisons should also be performed for known pressure gradients, a larger range of Reynolds numbers, and for a variety of surface roughness patterns. So far, this demonstration is incomplete. Clearly, this tracking device must be built and tested. A definitive set of criteria for selecting the control law parameters, one that includes the effects of the probe hardware, must be developed. However, the results presented in this paper are very encouraging. The simulation results clearly confirm that the tracking probe can be designed to accurately measure the skin friction in a real-time environment. 


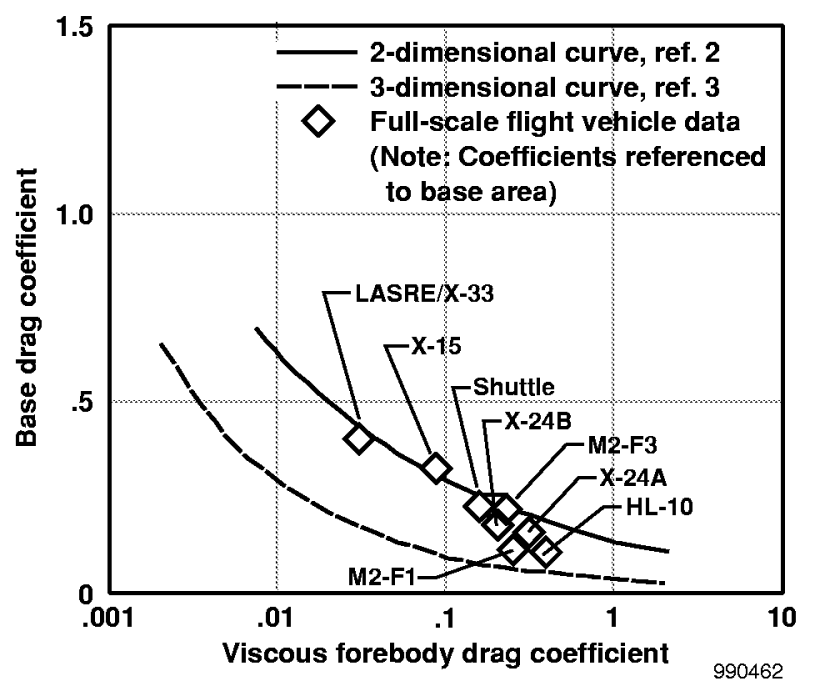

Figure 1. Subsonic correlation of base and viscous forebody drag coefficients.

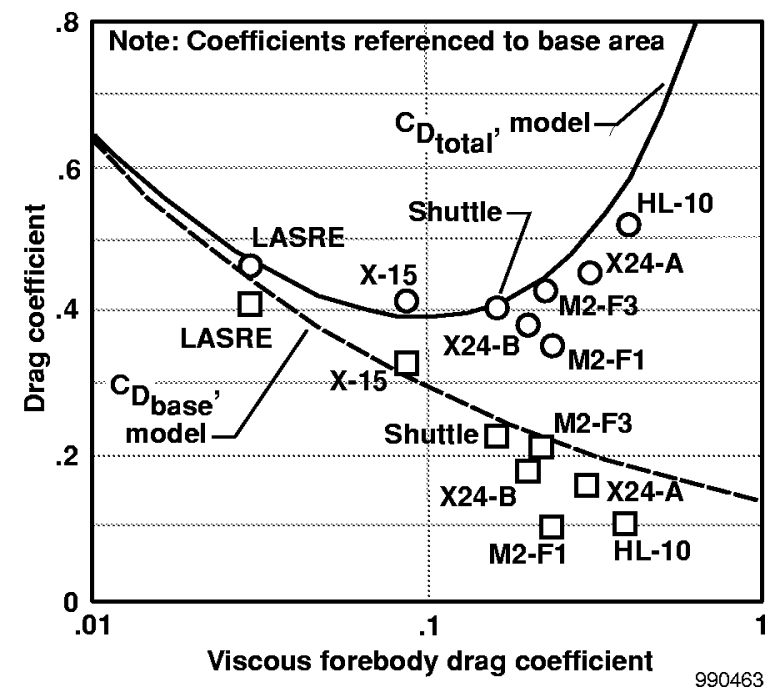

Figure 2. Visualization of the drag bucket. 


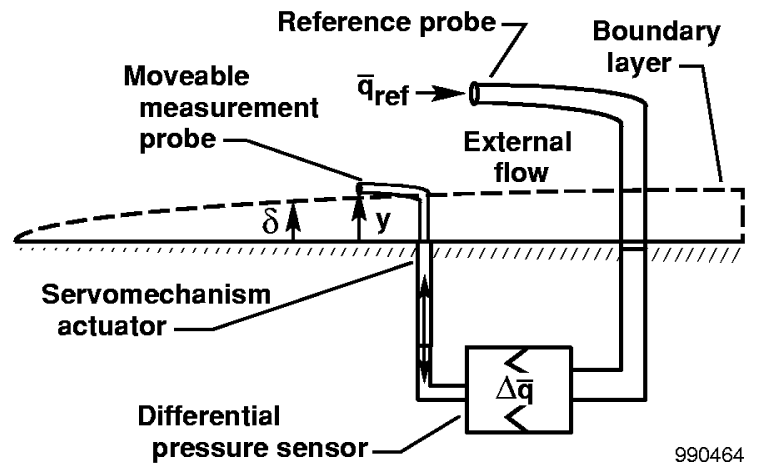

Figure 3. Conceptual schematic of boundary layer tracking probe.

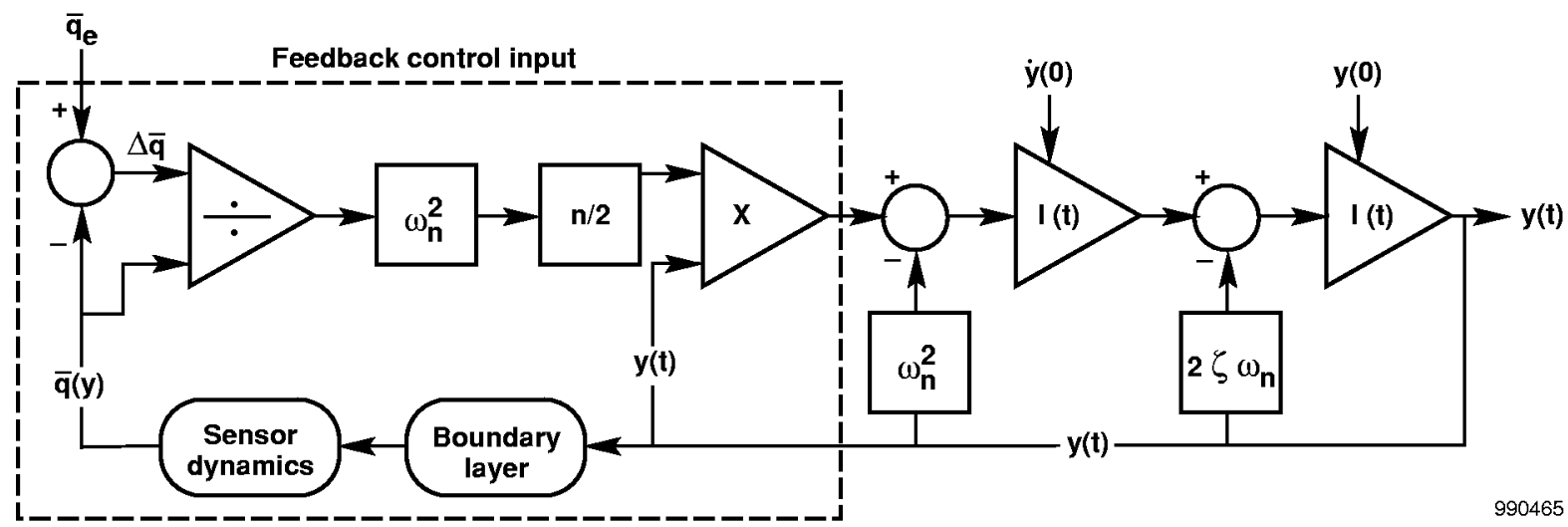

Figure 4. Analog flow diagram of boundary layer probe control law. 


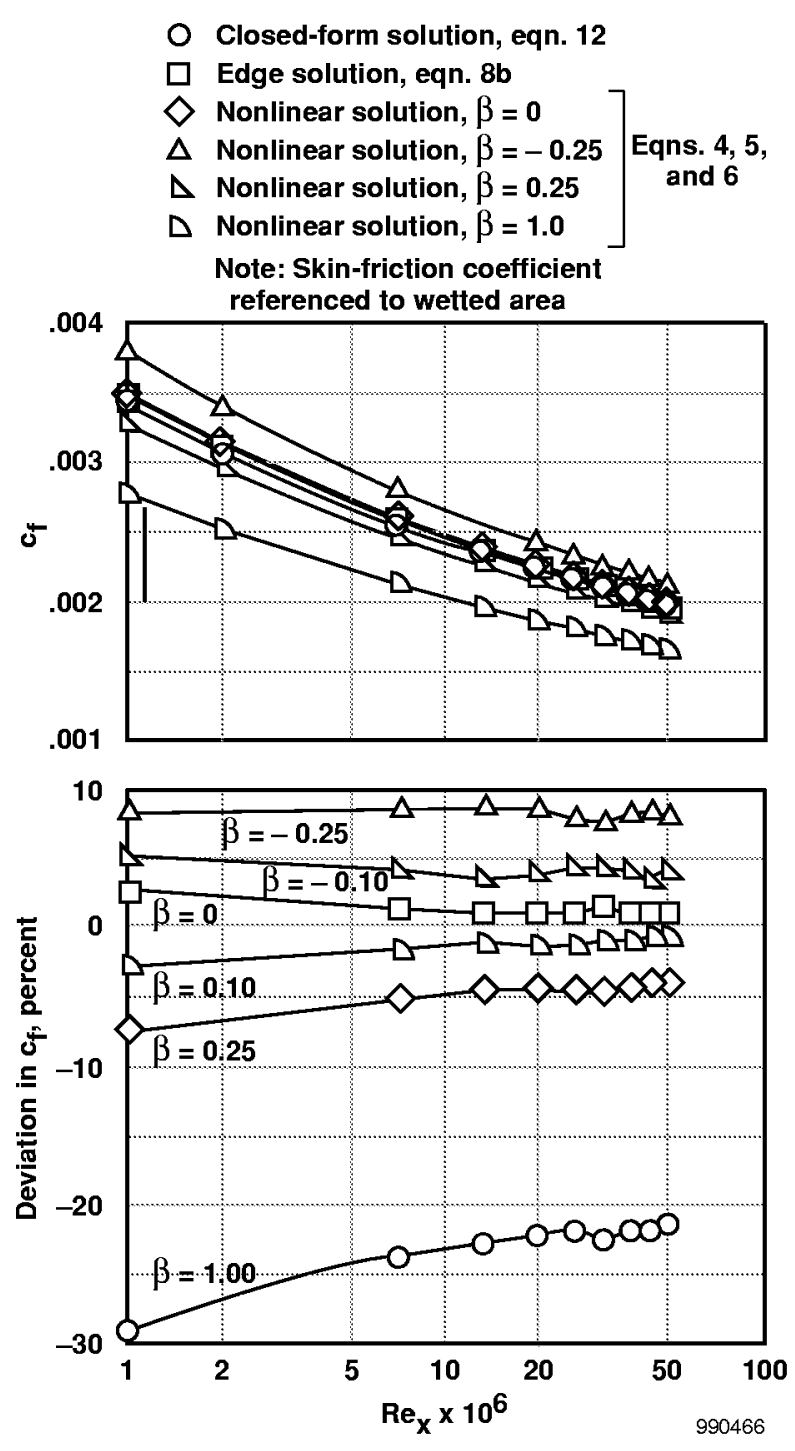

Figure 5. Effect of pressure gradient on the law of the wake solution methods. 

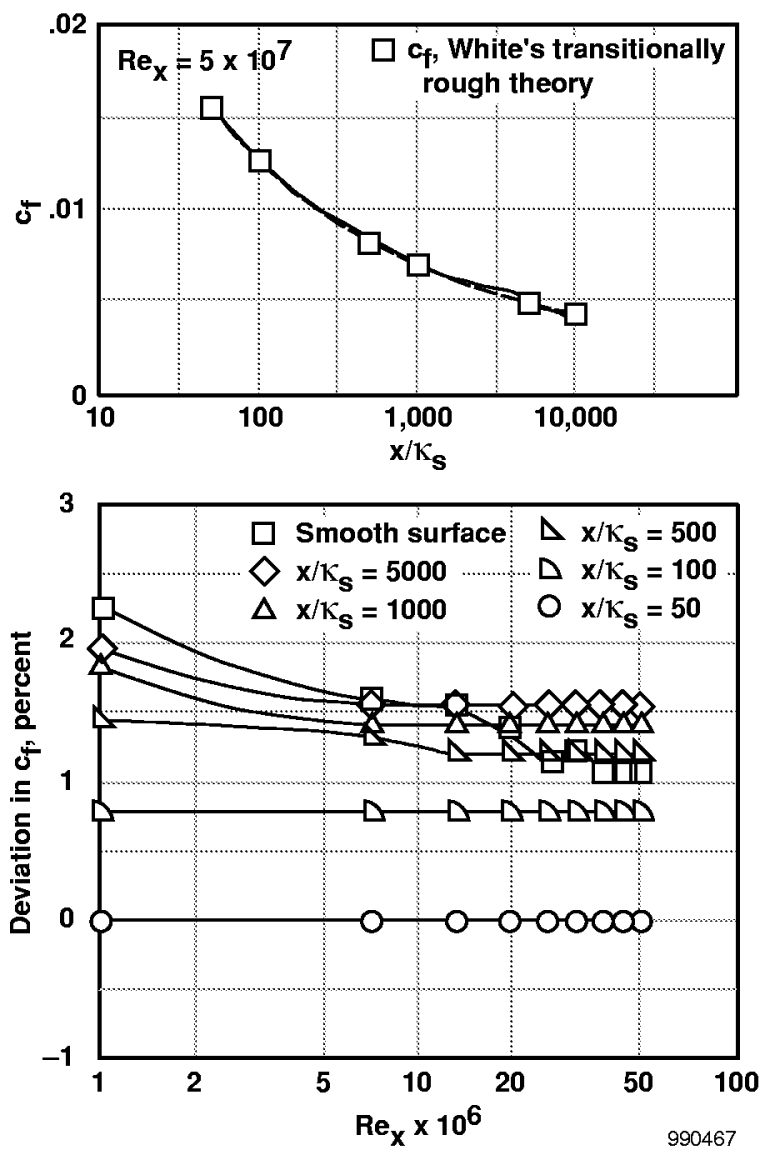

Figure 6. Effect of surface roughness on the law of the wake solution methods.

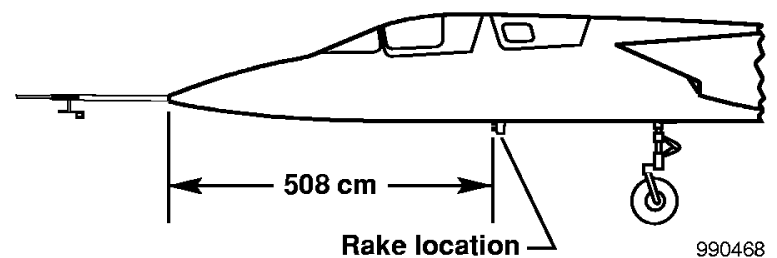

Figure 7. Schematic showing location of boundary layer instrumentation on A-5A aircraft. 

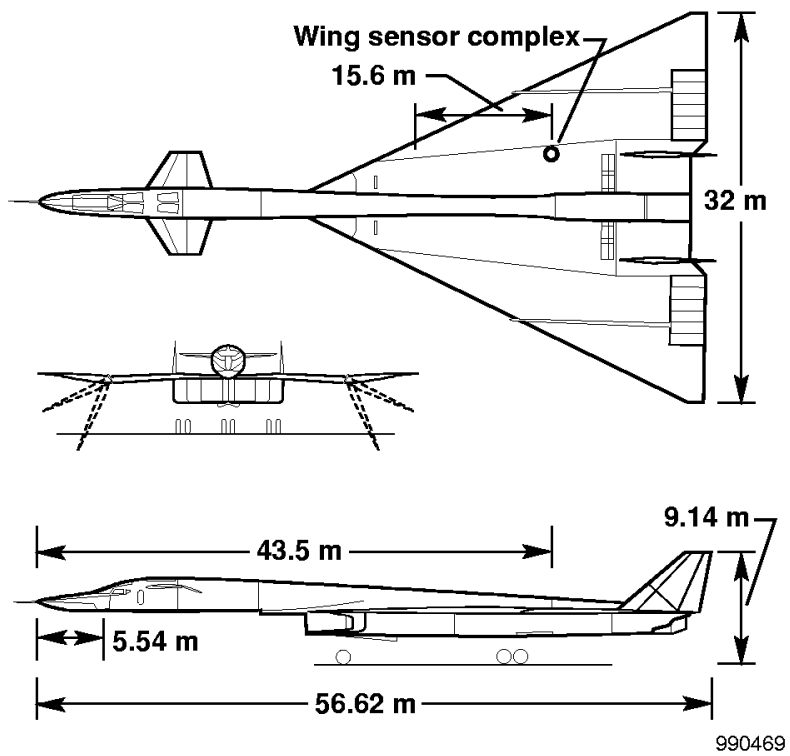

Figure 8. Schematic showing location of boundary layer instrumentation on XB-70-1 aircraft.

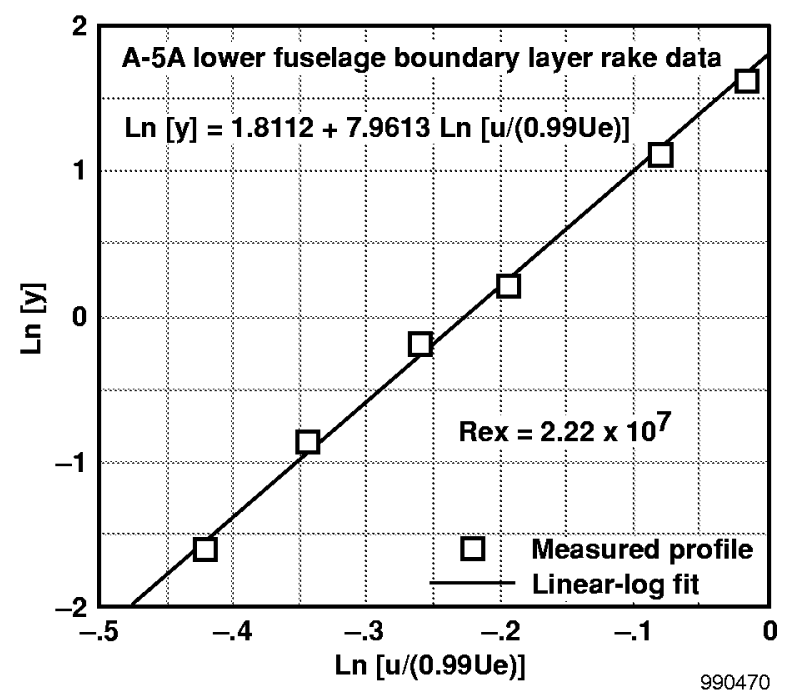

Figure 9. Linear-log plot of boundary layer rake data. 

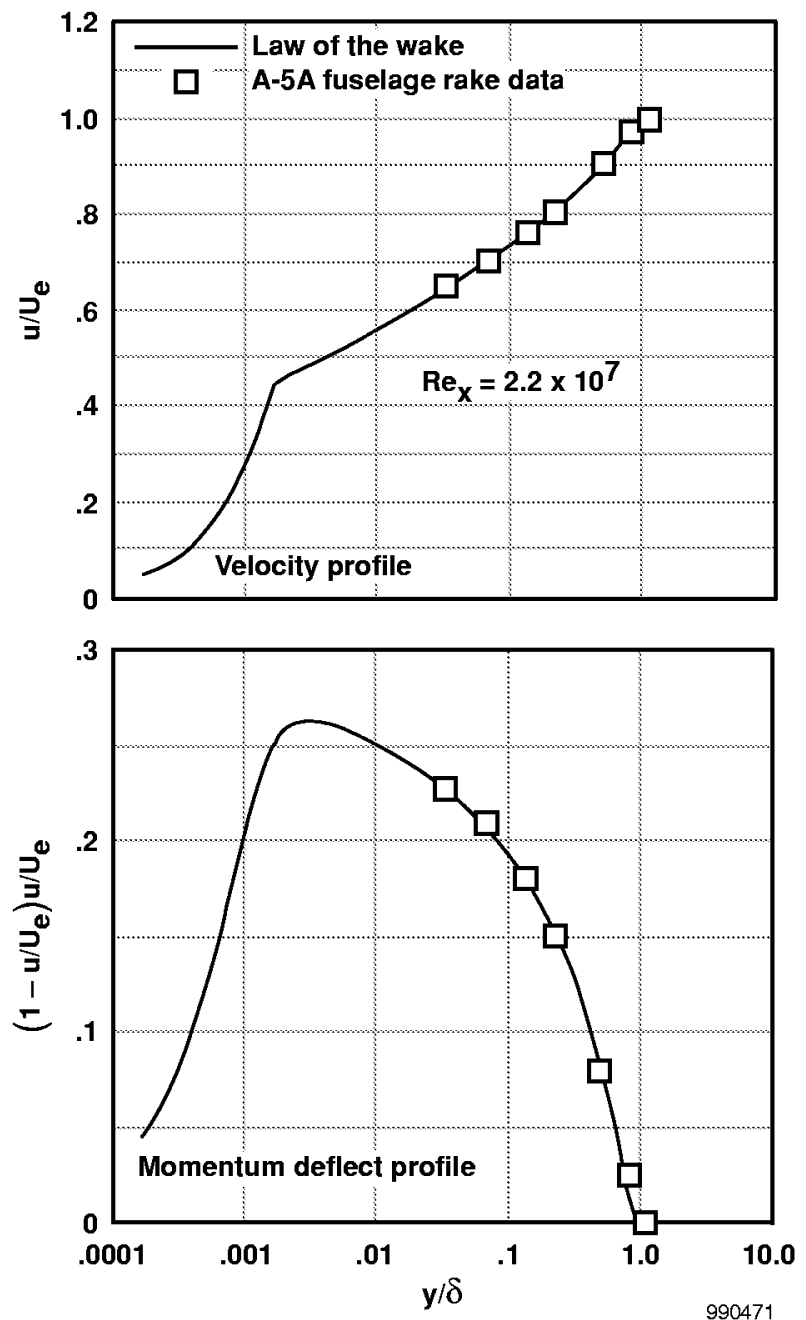

Figure 10. Comparison of law of the wake model against A-5A lower fuselage boundary layer rake. 

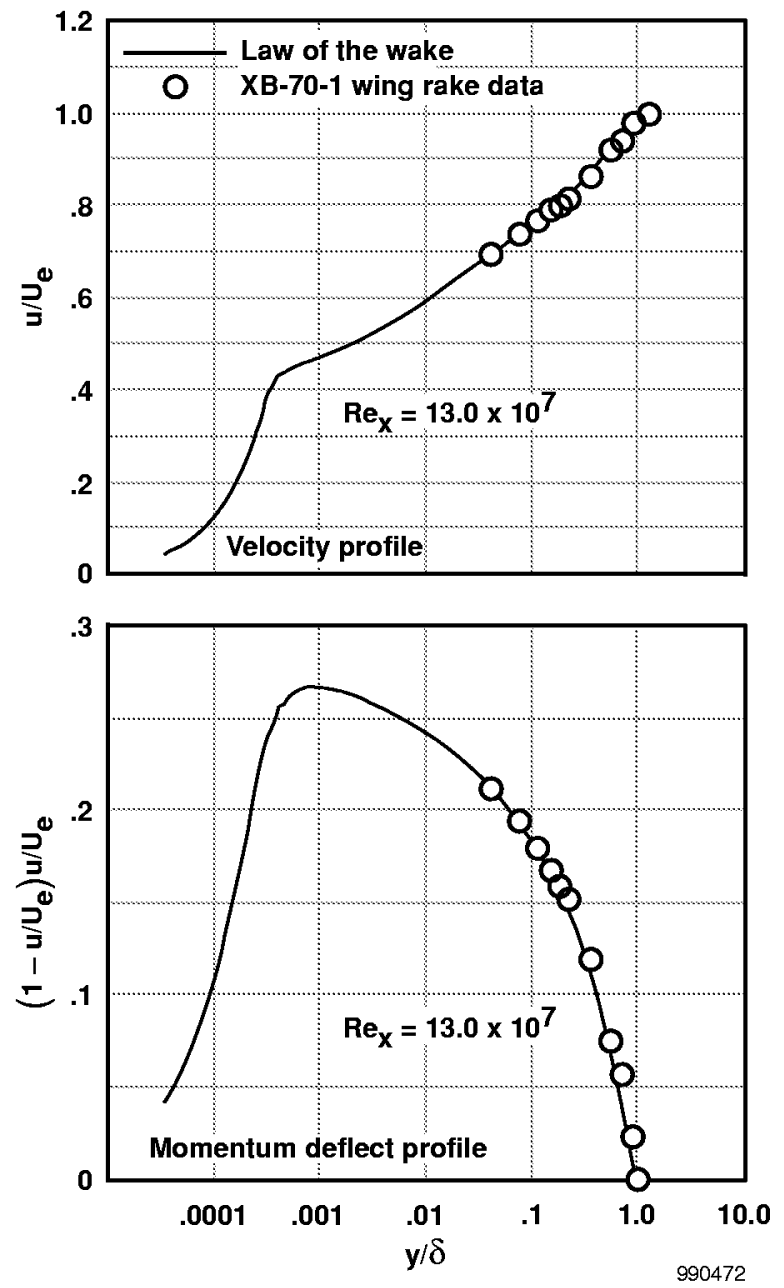

Figure 11. Comparison of law of the wake model against XB-70-1 wing surface boundary layer rake data. 


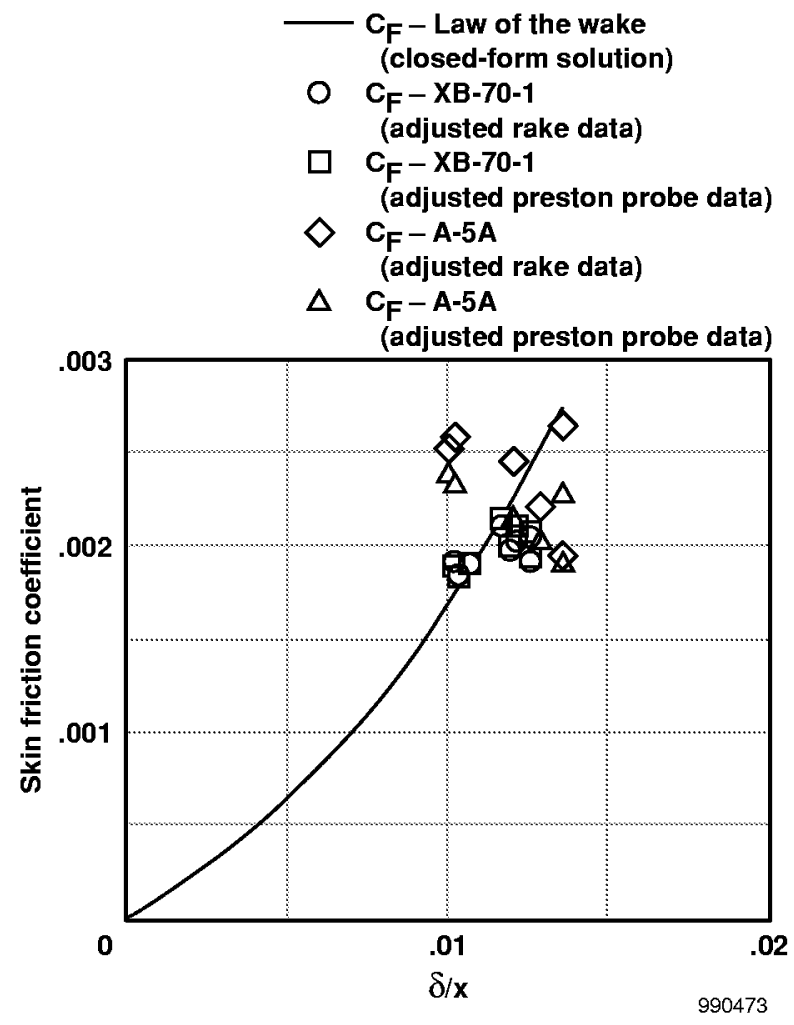

Figure 12. Summary of flight data, skin-friction coefficient comparisons. 


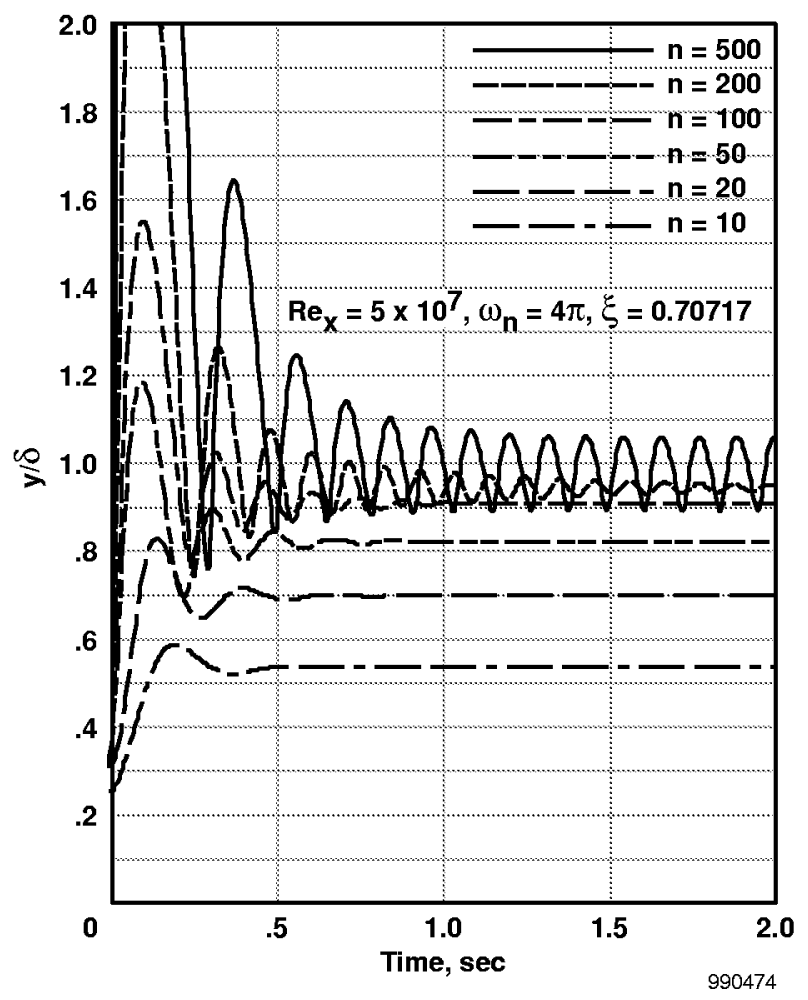

Figure 13. Effect of the control gain parameter on probe response.

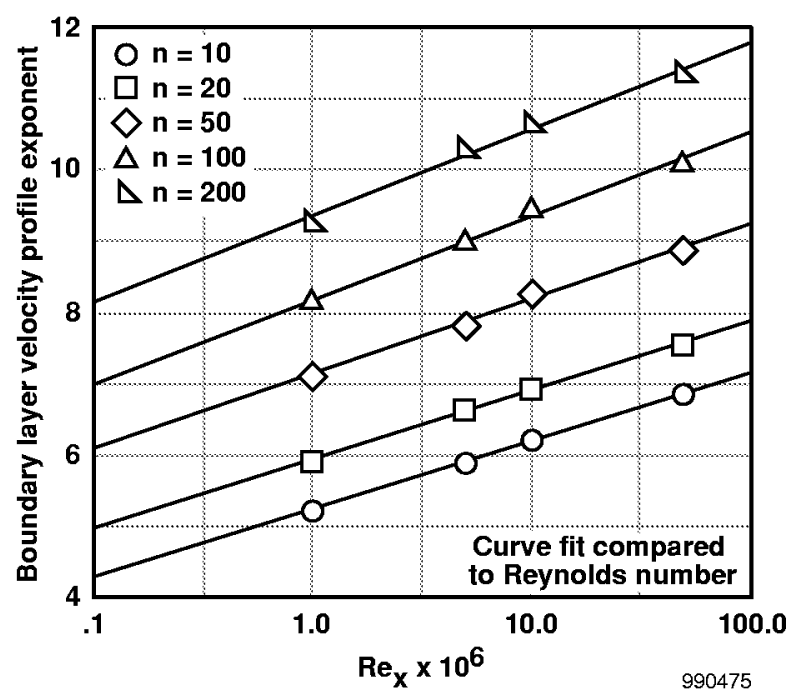

Figure 14. Velocity profile exponent. 

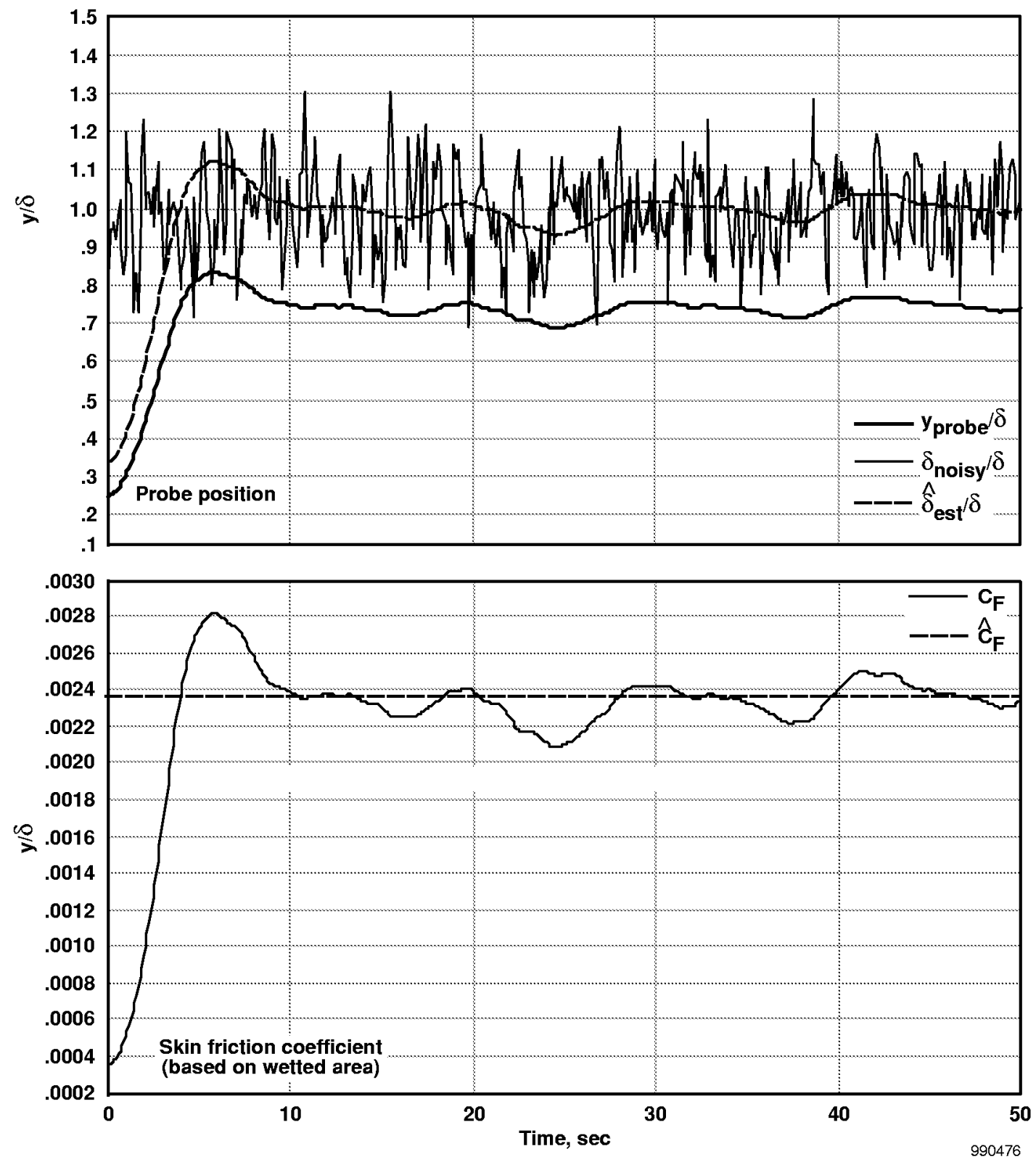

Figure 15. Response of probe control law to noisy boundary layer. 


\section{Appendix A: Integral}

Law-of-the-Wake Analysis

This analysis develops an integral relationship that relates the longitudinally averaged skin-friction coefficient to a local measurement of the boundary layer thickness. The analysis is based on Coles' empirical "law of the wake." The law of the wake relates the outer (turbulent) boundary layer variables to the nondimensionalized boundary layer coordinates and can be written in terms of the velocity defect as

$$
\begin{aligned}
& {\left[1-\frac{u(y)}{U_{e}}\right]=} \\
& \sqrt{\frac{C_{f}}{2}}\left[4.878 \Pi\left\{1-\sin ^{2}\left[\frac{\pi}{2} \frac{y}{\delta}\right]\right\}-2.439 \ln \left[\frac{y}{\delta}\right]\right]= \\
& {\left[1-\frac{u(y)}{U_{e}}\right]=} \\
& \sqrt{\frac{c_{f}}{2}}\left[4.878 \Pi \cos ^{2}\left[\frac{\pi y}{2} \frac{y}{\delta}\right]-2.439 \ln \left[\frac{y}{\delta}\right]\right]
\end{aligned}
$$

In equation $\mathrm{A}-1, \Pi$ is the wake parameter and is proportional to the local pressure gradient. Equation A-1 is a general expression that is valid outside of the laminar sublayer for plates, curved surfaces, surfaces with longitudinal pressure gradients, and rough surfaces. For a flat plate with zero pressure gradient, the wake parameter has an approximate numerical value of $\Pi \sim 0.55$.

\section{Correction for Laminar Sublayer}

Outside of the laminar sublayer, equation A-3 has been found to correlate well with measurements; however, within the laminar sublayer the correlation breaks down. In the laminar sublayer the correlation is better represented by the relationship, $u^{+}=y^{+}$, and the resulting velocity defect law in the laminar sublayer is

$$
1-\left[\frac{u}{U_{e}}\right]=1-\left[\frac{y}{\delta} \frac{\delta}{x} \operatorname{Re}_{\mathrm{x}} \frac{{ }^{c} f}{2}\right]=1-\sqrt{\frac{c_{f}}{2}} y^{+}
$$

Equation A-2 strictly holds for $y^{+}<5$ and equation A-1 strictly holds for $y^{+}>25$. Between these limiting values, the boundary layer velocity profile is transitional. Spalding ${ }^{20}$ has offered a transitional formula for this buffer layer; but with minimal loss in accuracy a simpler model can be developed by equating $\mathrm{A}-1$ and $\mathrm{A}-2$

$$
\begin{aligned}
1-\sqrt{\frac{c_{f}}{2}} y_{\text {trans }}+= & \sqrt{\frac{c_{f}}{2}}\left[4.878 \Pi \cos 2\left[\frac{\pi}{2} \frac{y_{\text {trans }}}{\delta}\right]\right. \\
& \left.-2.439 \ln \left[\frac{y_{\text {trans }}}{\delta}\right]\right]
\end{aligned}
$$

Allowing that the cosine term in equation A-3 is approximately 1, equation A-3 may be solved numerically, to produce

$$
y_{\text {trans }}^{+} \approx 10.81
$$

Thus for $y^{+}<10.81$ equation A-2 is used as the velocity defect model and for $y^{+} \geq 10.81$ equation A-1 is used as the velocity defect model.

\section{Momentum and Displacement Thickness Calculation}

The fundamental definitions for the (incompressible) momentum and displacement thickness are

$$
\begin{gathered}
\theta=\int_{0}^{\delta} \frac{u(y)}{U_{e}}\left[1-\frac{u(y)}{U_{e}}\right] d y \\
\delta^{*}=\int_{0}^{\delta}\left[1-\frac{u(y)}{U_{e}}\right] d y
\end{gathered}
$$

If the integrals of equations A-5 and A-6 are integrated across the depth of the boundary layer, using equation A-2 to evaluate the velocity defect within the laminar sublayer $\left(y^{+}<10.81\right)$ and equation A-1 in the turbulent layer $\left(y^{+}>10.81\right)$, then an integral form of the law of the wake can be derived. The laminar contribution to the momentum and displacement thickness are given as

$$
\begin{gathered}
\theta_{\text {lam }}=58.428 \frac{x}{\operatorname{Re}_{\mathrm{x}}}\left\{1-7.207 \sqrt{\frac{c_{f}}{2}}\right\}= \\
\delta_{\text {lam }}^{*}=58.428 \frac{x}{\operatorname{Re}_{\mathrm{x}}}
\end{gathered}
$$


The turbulent contribution is given as

$$
\begin{aligned}
\delta_{t u r b}^{*}= & \left(\delta \sqrt{c_{f}}-15.288 \frac{x}{\operatorname{Re}_{\mathrm{x}}}\right) \\
& \{1.72463[\Pi+1]\}
\end{aligned}
$$

Adding the laminar contributions and turbulent contributions together the total normalized momentum and displacement thickness equations become

$$
\begin{aligned}
\frac{\theta}{x}= & \left(\frac{\delta}{x} \sqrt{c_{f}}\right)\{1.72463[\Pi+1]\} \\
& -\sqrt{c_{f}}\left[4.46154 \Pi^{2}+9.45545 \Pi+5.9486\right] \\
& +\frac{1}{\operatorname{Re}_{\mathrm{x}}}[32.0797-26.3483 \Pi] \\
& +68.208 \sqrt{c_{f}}[\Pi-0.978711][\Pi+3.09803]
\end{aligned}
$$

and

$$
\begin{aligned}
\frac{\delta^{*}}{x}= & \left(\frac{\delta}{x} \sqrt{{ }^{c} f}\right)\{1.72463[\Pi+1]\} \\
& +\frac{[32.0805-26.3483 \Pi]}{\operatorname{Re}_{\mathrm{x}}}
\end{aligned}
$$

Relationship of Wake Parameter to Local Pressure Gradient

As mentioned earlier in this appendix, the wake parameter $(\Pi)$ is related to the local pressure gradient. The wake parameter has been correlated to the local pressure gradient by White ${ }^{20}$ as a polynomial curve fit of the form

$$
0.42 \Pi^{2}+0.76 \Pi-0.545=\beta \equiv \frac{\delta}{c_{f}} \frac{\frac{\partial p}{\partial x}}{\bar{q}}
$$

In equation A-13 $\beta$ is the Clauser parameter. Solving for $\Pi$ in terms of $\beta$ and substituting into equations A-11 and A-12 the momentum thickness and displacement thickness equations can be written with the nondimensional pressure gradient as an explicit parameter in the equations

$$
\begin{aligned}
\frac{\theta}{x}= & \frac{\delta}{x} \sqrt{c_{f}}\left[\begin{array}{c}
{[0.16425+2.66116 \sqrt{0.88881+\beta}]} \\
-[10.4874+10.6227 \beta+2.13276 \sqrt{0.88881+\beta}] \sqrt{c_{f}}
\end{array}\right] \\
& +\frac{55.9194-40.6563 \sqrt{0.88881+\beta}}{\operatorname{Re}_{\mathrm{x}}} \\
& +\frac{\sqrt{c_{f}}[-137.422+162.4 \beta+32.6051 \sqrt{0.88881+\beta}]}{\operatorname{Re}_{\mathrm{x}}}
\end{aligned}
$$

and

$$
\begin{aligned}
\frac{\delta^{*}}{x}= & \frac{\delta}{x} \sqrt{c_{f}}[[0.16425+2.66116 \sqrt{0.88881+\beta}]] \\
& +\frac{55.9194-40.6563 \sqrt{0.88881+\beta}}{\operatorname{Re}_{\mathrm{x}}}+
\end{aligned}
$$




\section{Appendix B: Unsteady Boundary Layer Model}

In a real-world turbulent boundary layer there are random elements whose characteristics can only be statistically predicted. Mathematically, this random element is treated by decomposing the boundary layer velocity components into time-mean and perturbation components.

$$
\begin{aligned}
u[x, y, z, t] & =U[x, y, z]+u^{\prime}[x, y, z, t] \\
v[x, y, z, t] & =V[x, y, z]+v^{\prime}[x, y, z, t] \\
w[x, y, z, t] & =W[x, y, z]+w^{\prime}[x, y, z, t]
\end{aligned}
$$

The point-to-point variations of the perturbation components are inherently intermittent and can never be theoretically predicted. The law-of-the-wake analysis presented in the paper deals only with the time averaged velocity components of the boundary layer. However, the dynamic flow components will effect the performance of the boundary layer tracking probe and this flow intermittency must be modeled in the probe simulation. In this paper the random components within the boundary layer are modeled using data taken from Klebanoff. ${ }^{19}$ The intermittency factor is the fraction of time that the flow is turbulent at a given perpendicular distance away from the wall. The intermittency factor is plotted as a function of the normalized perpendicular distance in figure B-1. The raw data from Klebanoff's report are presented along with a curve-fit model

$$
\gamma=\left[1+5\left[\frac{y}{\delta}\right]^{6}\right]^{-1.4}
$$

This intermittency function is used as a probability density function which describes the time distribution of a particular velocity component. Assuming that the time-mean $y$ and $z$ velocity distributions are approximately zero, then the intermittent boundary layer model is written as

$$
\begin{aligned}
u[x, y, z, t] & =U[x, y, z]+\left|u^{\prime}\right| \gamma \eta[t] \\
v[x, y, z, t] & =\left|v^{\prime}\right| \gamma \eta[t] \\
w[x, y, z, t] & =\left|w^{\prime}\right| \gamma \eta[t]
\end{aligned}
$$

In equation B-3 $\eta(t)$ is a uniformly distributed random number, and the terms $|u|,|v|$, and $|w|$ are the expected values for the perturbation magnitudes. These parameters are also derived from curve fits of data presented by Klebanoff. These data are presented in Figure B-2. The unusual shape of the data curves was difficult to curve-fit. Instead these data were loaded into the simulation as tables and their values were computed as a function of $y / \delta$ using a log-linear interpolation.

The resulting model produces a boundary layer with a ragged shape. In the outer regions of the boundary layer there are turbulent fluctuations which extend beyond the normally defined boundary layer edge. Conversely, there are intermittent regions inside of the normally defined boundary layer where the velocity is equal to the free-stream velocity. At each time point the dynamic pressure profile within the boundary layer is computed by taking the inner produce of the velocity components in equation B-3 and using this result to scale the undisturbed dynamic pressure profile.

$\bar{q}_{u n s t e a d y}=\left[1+\frac{2 U u^{\prime}+u^{\prime 2}+v^{\prime 2}+w^{\prime 2}}{U^{2}}\right] \bar{q}_{\text {steady }}$

In equation B-4 $u^{\prime}, v^{\prime}$, and $w^{\prime}$ are the random velocity perturbations evaluated using the formulas of equation $\mathrm{B}-3$, and $U$ is the steady longitudinal velocity in the boundary layer at location $y$. The intermittent boundary layer thickness is computed as the value of $y$ where

$$
\delta \rightarrow \sqrt{U^{2}+2 U u^{\prime}+u^{\prime 2}+v^{\prime 2}+w^{\prime 2}}=U_{e}
$$




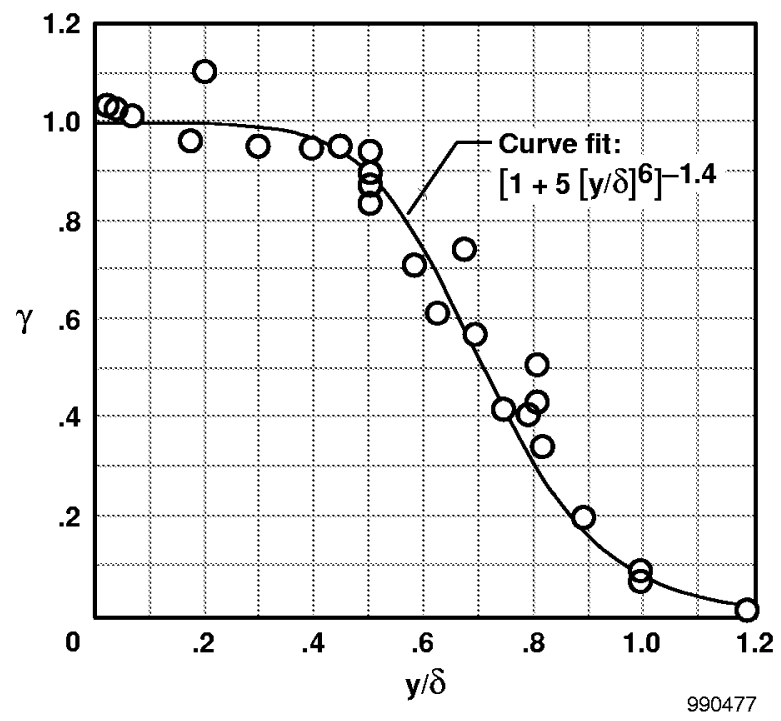

Figure B-1. Boundary layer intermittency factor.

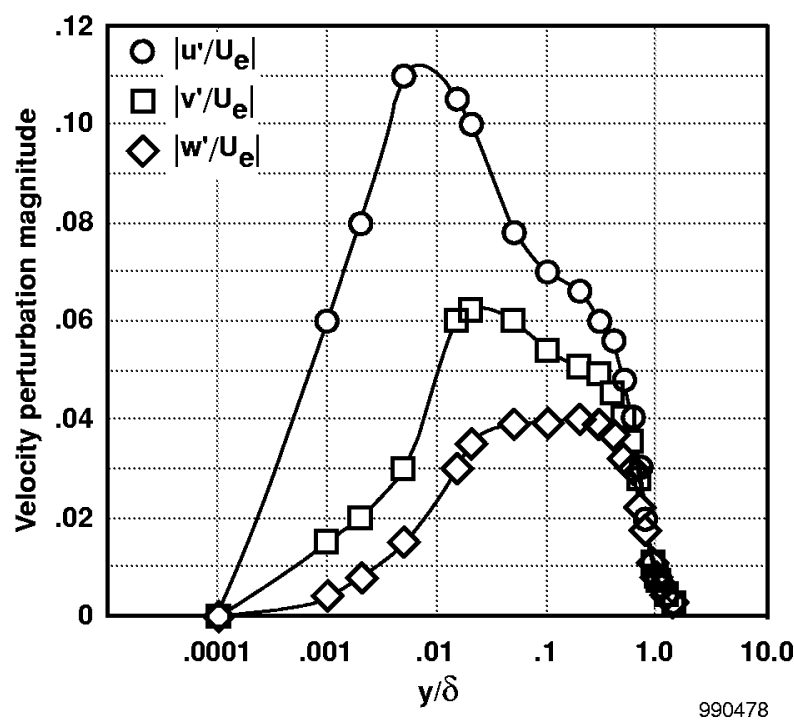

Figure B-2. Fluctuating velocity components in the turbulent boundary layer. 


\section{$\underline{\text { References }}$}

1 Wong, Thomas J., Charles A. Hermach, John O. Reller, Jr., and Bruce E. Tinling, Preliminary Studies of Manned Satellites-Wingless Configurations: The Lifting Body, NACA Conference on High-Speed Aerodynamics: A Compilation of the papers presented, NASA TM X-67369, 1958.

${ }^{2}$ Hoemer, Sighard F., Fluid-Dynamic Drag, SelfPublished, Brick Town, New Jersey, 1965.

${ }^{3}$ Saltzman, Edwin J., K. Charles Wang, and Kenneth W. Iliff, "Flight-Determined Subsonic Lift and Drag Characteristics of Seven Lifting-Body and Wing-Body Reentry Vehicle Configurations With Truncated Bases," AIAA Paper 99-0383, January 1999.

${ }^{4}$ Whitmore, Stephen A., and Timothy R. Moes, "A Base Drag Reduction Experiment on the X-33 Linear Aerospike SR-71 Experiment (LASRE) Flight Program," AIAA 99-0277, January 1999.

${ }^{5}$ Miller, Linda, Michael Hect, Martin Buehler, Amin Mottiwala, Beverly Eyre, and Indrani Chakraborty, "Ceramic Hybrid Electromechanical Systems (CHEMS)," NASA Tech Briefs, Vol. 23, No. 2, February 1999, pp. 61-62.

${ }^{6}$ Coles, Donald, "The law of the wake in the turbulent boundary layer," Journal of Fluid Mechanics, Vol. 1, 1956, pp. 191-226.

${ }^{7}$ Garringer, Darwin J., and Edwin J. Saltzman, Flight Demonstration of a Skin-Friction Gage to a Local Mach. Number of 4.9, NASA TN D-3830, Feb. 1967.

${ }^{8}$ Quinn, Robert D., and Frank V. Olinger, FlightMeasured Heat Transfer and Skin Friction at a Mach Number of 5.25 and at Low Wall Temperatures, NASA TM X-1921, November 1969.

${ }^{9}$ Naughton, J. W., and J. L. Brown, "Surface Interferometric Skin-Friction Measurement Technique," AIAA Paper 96-2183, June 1996.

\footnotetext{
${ }^{10}$ Hopkins, Edward J., and Earl R. Keener, Study of Surface Pitots for Measuring Turbulent Skin Friction at
}

Supersonic Mach Numbers-Adiabatic Wall, NASA TN-D-3478, July, 1966.

${ }^{11}$ Keener, Earl R., and Edward J. Hopkins, Accuracy of Pitot-Pressure Rakes for Turbulent Boundary-Layer Measurements in Supersonic Flow, NASA TN D-6229, March 1971.

${ }^{12}$ Mills, Anthony F., Heat and Mass Transfer, Irwin Publishing Co., Homewood, Illinois, 1992.

${ }^{13}$ Clauser, Francis H., "Turbulent Boundary Layers in Adverse Pressure Gradients," Journal of Aeronautical Sciences, Vol. 21, No. 2, 1954.

${ }^{14}$ White, Frank M., Viscous Fluid Flow, McGrawHill, Inc., New York, 1991.

${ }^{15}$ Mills, A. F. and Xu Huang, "On the Skin Friction for a Fully Rough Flat Plate," Journal of Fluids Engineering, Technical Briefs, Vol. 105, September 1983, pp. 364-365.

${ }^{16}$ Rade, Lennart, and Bertil Westergren, Beta Mathematics Handbook, 2nd ed., CRC Press Inc., Boca Raton, Florida, 1990.

${ }^{17}$ Fisher, David F., and Edwin J. Saltzman, Local Skin Friction Coefficients and Boundary-Layer Profiles Obtained in Flight from the XB-70-1 Airplane at Mach Numbers up to 2.5, NASA TN D-7220, June 1973.

${ }^{18}$ Saltzman, Edwin J., and David F. Fisher, Some Turbulent Boundary-Layer Measurements Obtained from the Forebody of an Airplane at Mach Numbers up to 1.72, NASA TN D-5838, June 1970.

${ }^{19}$ Klebanoff, P. S., Characteristics of Turbulence in a Boundary Layer with Zero Pressure Gradient, NACA Report 1247, 1955.

${ }^{20}$ Spalding, D. B., and S. W. Chi, "The Drag of a Compressible Turbulent Boundary Layer on a Smooth Flat Plate With and Without Heat Transfer," Journal of Fluid Mechanics, Vol. 18, 1964, Cambridge University Press, New York, New York, pp. 117-143. 
Public reporting burden for this collection of information is estimated to average 1 hour per response, including the time for reviewing instructions, searching existing data sources, gathering and maintaining the data needed, and completing and reviewing the collection of information. Send comments regarding this burden estimate or any other aspect of this collection of information, including suggestions for reducing this burden, to Washington Headquarters Services, Directorate for Information Operations and Reports, 1215 Jefferson Davis Highway, Suite 1204, Arlington, VA 22202-4302, and to the Office of Management and Budget, Paperwork Reduction Project (0704-0188), Washington, DC 20503.

1. AGENCY USE ONLY (Leave blank)

2. REPORT DATE

3. REPORT TYPE AND DATES COVERED

January 2000

Technical Memorandum

4. TITLE AND SUBTITLE

A Real-Time Method for Estimating Viscous Forebody Drag Coefficients

6. AUTHOR(S)

WU 529-50-04-T2-RR-00-000

Stephen A. Whitmore, Marco Hurtado, Jose Rivera, and Jonathan W.

Naughton

7. PERFORMING ORGANIZATION NAME(S) AND ADDRESS(ES)

NASA Dryden Flight Research Center

P.O. Box 273

Edwards, California 93523-0273

8. PERFORMING ORGANIZATION

REPORT NUMBER

H-2394

9. SPONSORING/MONITORING AGENCY NAME(S) AND ADDRESS(ES)

10. SPONSORING/MONITORING AGENCY REPORT NUMBER

National Aeronautics and Space Administration

Washington, DC 20546-0001

NASA/TM-2000-209015

\section{SUPPLEMENTARY NOTES}

Presented as AIAA 2000-0781 at the 38th Aerospace Sciences Meeting and Exhibit, January 10-13, 2000, Reno, Nevada.

Stephen A. Whitmore and Marco Hurtado, NASA Dryden Flight Research Center, Edwards, CA; Jose Rivera, University of South Florida, Tampa, FL; and Jonathan W. Naughton, University of Wyoming, Laramie, WY.

12a. DISTRIBUTION/AVAILABILITY STATEMENT

12b. DISTRIBUTION CODE

Unclassified-Unlimited

Subject Category 05

This report is available at http://www.dfrc.nasa.gov/DTRS/

13. ABSTRACT (Maximum 200 words)

This paper develops a real-time method based on the law of the wake for estimating forebody skin-friction coefficients. The incompressible law-of-the-wake equations are numerically integrated across the boundary layer depth to develop an engineering model that relates longitudinally averaged skin-friction coefficients to local boundary layer thickness. Solutions applicable to smooth surfaces with pressure gradients and rough surfaces with negligible pressure gradients are presented. Model accuracy is evaluated by comparing model predictions with previously measured flight data. This integral law procedure is beneficial in that skin-friction coefficients can be indirectly evaluated in real-time using a single boundary layer height measurement. In this concept a reference pitot probe is inserted into the flow, well above the anticipated maximum thickness of the local boundary layer. Another probe is servomechanism-driven and floats within the boundary layer. A controller regulates the position of the floating probe. The measured servomechanism position of this second probe provides an indirect measurement of both local and longitudinally averaged skin friction. Simulation results showing the performance of the control law for a noisy boundary layer are then presented.

14. SUBJECT TERMS

Base drag, Boundary layer, Hypersonic vehicles, Skin friction

15. NUMBER OF PAGES

34

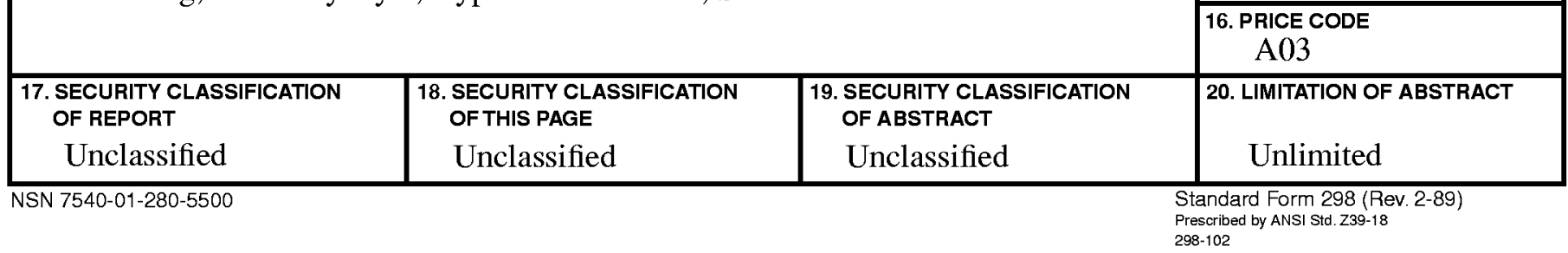

